Linköping University Medical Dissertations No. 1504

\title{
Challenges in experimental stroke research
}

\section{The $17 \beta$-estradiol example}

\author{
Edvin Ingberg
}

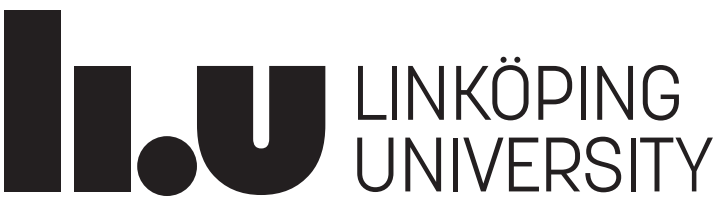

Department of Clinical and Experimental Medicine,

Faculty of Medicine and Health Sciences, Linköping University, Sweden 
(c) Edvin Ingberg, 2016

Cover: A simplified illustration of the middle cerebral artery, including its origin and branches. Made by the author.

Published articles and figures have been reprinted with permission from the respective copyright holders.

Linköping University Medical Dissertations No. 1504 ISBN: 978-91-7685-852-3

ISSN: 0345-0082

Printed by LiU-tryck in Linköping, Sweden, 2016. 
For all that has been - Thanks! To all that shall be - Yes!

Dag Hammarskjöld (Markings) 


\section{Contents}

Abbreviations $\quad 5$

List of papers 6

Abstract $\quad 7$

Populärvetenskaplig sammanfattning 9

$\begin{array}{ll}\text { 1. Background } & 11\end{array}$

1.1. Stroke 11

1.2. Animal models of cerebral ischemia 13

1.3. Methodological issues in experimental stroke $\quad 15$

1.4. The effects of estrogens on ischemic stroke 18

2. Hypothesis 25

3. Aims 26

4. Material and Methods 27

4.1. Overview of study designs 27

4.2. Experimental studies (Papers I and IV) 29

4.3. Meta-analytical studies (Papers II, III and V) 37

5. Results and Discussion $\quad 44$

5.1. Differences between administration methods (Paper I) 44

5.2. Estrogens and stroke - aspects of administration methods 46 and dose (Papers III and IV)

5.3. Method parameters' impact on mortality and variability 51 in rodent stroke experiments (Papers II and V)

5.4. Strengths and weaknesses of the thesis 55

5.5. Future perspectives 58

6. Acknowledgements $\quad 60$

7. References 61

$\begin{array}{ll}\text { Paper I } & 71\end{array}$

Methods for long-term 17 $\beta$-estradiol administration to mice

Paper II

Method parameters' impact on mortality and variability in

rat stroke experiments: a meta-analysis

Paper III

Impact of methodology on estrogens' effects on cerebral ischemia in rats: an updated meta-analysis

Paper IV

Effects of high and low $17 \beta$-estradiol doses on focal

cerebral ischemia in rats

Paper V

Method parameters' impact on mortality and variability

in mouse stroke experiments: a meta-analysis 


\section{Abbreviations}

AMPA - $\alpha$-amino-3-hydroxy-5-methyl-4-isoxazolepropionic acid

ANOVA - Analysis of variance

ATP - Adenosine triphosphate

BBB - Blood brain barrier

CAMARADES - Collaborative approach to meta-analysis and review of animal data from experimental studies

CCA - Common carotid artery

DALY - Disability adjusted life years

DNA - Deoxyribonucleic acid

DPN - Diarylpropionitrile

ECA - External carotid artery

EC-ratio - Infarct size ratio between estrogen treated and control rats in Paper III

ELISA - Enzyme-linked immunosorbent assay

ER - Estrogen receptor

FSH - Follicle-stimulating hormone

GnRH - Gonadotropin-releasing hormone

GPER - G-protein coupled estrogen receptor 1

HERS - Heart and estrogen-progestin replacement study

HRT - Hormone replacement therapy

ICA - Internal carotid artery

IRA - Innovative research of America

LDF - Laser Doppler flowmetry

LH - Luteinizing hormone

MCA - Middle cerebral artery

MCAo - Middle cerebral artery occlusion

MMP - Matrix metalloproteinases

MPP - Methyl piperidino pyrazole

MST - Modified sticky tape test

NMDA - N-methyl-D-aspartate

PPT - Propyl pyrazole triol

R,R-THC - R-R-tetrahydrochrysene

RIA - Radioimmunoassay

ROS - Reactive oxygen species

SHBG - Sex hormone-binding globulin

STAIR - Stroke therapy academic industry roundtable

SYRCLE - Systematic review centre for laboratory animal experimentation

TIA - Transient ischemic attack

tPA - Tissue plasminogen activator

TTC - 2,3,5-triphenyltetrazolium chloride

WHI - Women's health initiative 


\section{List of papers}

Paper I: Ingberg E, Theodorsson A, Theodorsson E, Ström JO. Methods for longterm 17 $\beta$-estradiol administration to mice. General and Comparative Endocrinology. 2012 Jan 1;175(1):188-93.

Paper II: Ström JO, Ingberg E, Theodorsson A, Theodorsson E. Method parameters' impact on mortality and variability in rat stroke experiments: a meta-analysis. BMC Neuroscience. 2013 Apr 1;14:41.

Paper III: Ström JO, Ingberg E. Impact of methodology on estrogens' effects on cerebral ischemia in rats: an updated meta-analysis. BMC Neuroscience. 2014 Feb 4;15:22.

Paper IV: Ingberg E, Theodorsson E, Theodorsson A, Ström JO. Effects of high and low $17 \beta$-estradiol doses on focal cerebral ischemia in rats. Manuscript.

Paper V: Ingberg E, Dock H, Theodorsson E, Theodorsson A, Ström JO. Method parameters' impact on mortality and variability in mouse stroke experiments: a metaanalysis. Accepted for publication in Scientific Reports. 


\section{Abstract}

Ischemic stroke causes millions of deaths around the world each year, and surviving patients often suffer from long-term disability. Hundreds of promising drug candidates have been identified in animal models, but the clinical trials have repeatedly failed. Lack of methodological quality in the animal studies, e.g. low statistical power as a result of small group sizes in combination with high outcome variability and high mortality, has been suggested to in part explain the lack of translational success. In the meta-analytical Papers II and V, we therefore investigated how method parameters impact infarct size variation and mortality in rodent stroke studies. These findings can help researchers to optimize their animal models or to more exactly predict variability and mortality given a certain experimental setup.

The relation between ischemic stroke and estrogens is complex. Premenopausal women have a lower risk of stroke than men of the same age, suggesting that female sex hormones provide protection against cerebrovascular events. The idea of a beneficial effect on the brain of estrogens was also supported by epidemiological studies showing that estrogens given as postmenopausal hormone replacement therapy decreased the risk of stroke. However, subsequent clinical trials reported the opposite, an increased risk. Interestingly, discrepancies exist also in the animal stroke literature. The majority of the rodent studies on the effects of estrogens have shown protection, but there are also several examples of increased damage. Based on experimental results and a meta-analysis, it was hypothesized that differences in hormone administration methods and their resulting plasma concentrations of estrogens might explain the previous discordant animal findings. Paper I investigated the commonly used methods for $17 \beta$-estradiol administration and found that the popular slow-release pellets produced high and unpredictable serum concentrations. A novel method with $17 \beta$-estradiol administered orally in Nutella ${ }^{\circledR}$ was also evaluated with promising results. Paper III extracted data regarding methodological choices from all previously published estrogen-stroke studies, and showed through metaanalysis that slow-release pellets are more prone to render estrogens damaging. Finally, Paper IV tested whether estrogens could both exert neuroprotection and promote detrimental effects merely depending on dose and irrespective of the administration route. Surprisingly, and in contrast to the hypothesis, a significant negative correlation was found between $17 \beta$-estradiol dose group and infarct size meaning that the higher the dose, the smaller the infarcts.

In summary, this thesis does not confirm the hypothesis of dose-related neuroprotective vs neurodamaging effects of estrogens on ischemic stroke. If high estrogen doses/ plasma concentrations per se can cause increased stroke damage, such a phenomenon is not very robust, and seems to depend on tight dose ranges and/or other experimental circumstances. Although not directly applicable to the clinical situation, hopefully in a long-term perspective these findings may contribute in elucidating when estrogens are beneficial and when they are harmful. Further, it adds to the growing literature on 
how the quality of experimental stroke research can be increased to try to overcome translational difficulties. 


\section{Populärvetenskaplig sammanfattning}

Stroke i form av hjärninfarkt orsakar miljoner dödsfall runt om i världen varje år, och av de patienter som överlever drabbas många av funktionsnedsättning. Forskning på djurmodeller av sjukdomen har identifierat hundratals lovande läkemedelskandidater, men resultat i kliniska studier på människor har varit nedslående. Det har föreslagits att dessa misslyckanden med att överföra resultat från djur till människa åtminstone delvis kan förklaras av brister i design och genomförande av djurstudierna. En viktig faktor tros vara att många studier har små gruppstorlekar i kombination med stor variation i utfallsmåttet och hög mortalitet, vilket påverkar tillförlitligheten i resultaten. I ett försök att bidra till förbättrad kvalitet samlade vi information från tidigare publicerade strokestudier gjorda på gnagare och analyserade statistiskt hur olika metodval påverkar variation i utfallsmåttet och mortalitet. Dessa studier, artikel II och V i avhandlingen, kan hjälpa forskare att förutsäga dessa två parametrar, mortalitet och variation i utfallsmått, och därmed underlätta design av och förbättra kvaliteten på sina strokestudier på gnagare.

Kopplingen mellan hjärninfarkt och det kvinnliga könshormonet östrogen är komplex. Kvinnor före klimakteriet har en lägre risk för stroke jämfört med män i samma ålder, vilket har lett till idén att kvinnliga könshormoner kan vara skyddande. Tidigare epidemiologiska studier gav också stöd för den uppfattningen genom att rapportera lägre risk för stroke hos kvinnor som efter klimakteriet behandlats med hormonersättning. Till mångas förvåning visade dock senare studier, där kvinnor följdes upp efter att ha slumpmässigt blivit tilldelade hormonersättning eller inte, på raka motsatsen, det vill säga högre strokerisk för kvinnor med hormonbehandling. Även i djurförsök, där man behandlat med östrogen och sedan orsakat en stroke hos djuret, går resultaten isär. Majoriteten av studierna har visat på en skyddande effekt av östrogen, men ett antal studier har också visat på ökad skada. Utifrån tidigare resultat från vår grupp och andra forskare, formulerades hypotesen att förklaringen till dessa varierande resultat skulle kunna vara skillnader i vilken metod som använts för att behandla djuren med östrogen, genom att ge upphov till olika hormonkoncentrationer i blodet. I artikel I undersöktes vanliga sätt att behandla möss med östrogen och vi fann att de ofta använda pelletarna som opereras in under huden, gav höga och ojämna koncentrationer. Dessutom testades en ny metod där östrogen serverades till mössen i Nutella ${ }^{\circledR}$. Nästa steg var att undersöka om olika metodval påverkar huruvida östrogen är skyddande eller skadande i råttstudier, och detta gjordes genom att, liksom för artikel II och V, samla och analysera information från tidigare publicerade studier. Resultaten (artikel III) visade att pelletarna, som tidigare visats ge höga koncentrationer av östrogen i blodet, oftare resulterade i ökad skada i samband med stroke jämfört med andra metoder att behandla råttorna med hormonet. Det sista steget var sedan att testa om östrogen kunde vara både skyddande och skadande för hjärnan i samband med stroke enbart beroende på dos, oavsett vilken behandlingsmetod som användes. Det experimentet, som resulterade i artikel IV, kunde dock inte styrka hypotesen om att dos är den viktiga faktorn som avgör om östrogen är skyddande 
eller inte. Det verkade snarare vara så att ju högre dos råttorna behandlades med, desto mindre hjärninfarkter fick de.

Sammanfattningsvis kan den aktuella avhandlingen inte bekräfta hypotesen att dos är den avgörande faktorn varför vissa tidigare experimentella strokestudier har visat på minskad skada med östrogenbehandling medan andra har visat på ökad skada. Om höga doser östrogen kan orsaka ökad skada i samband med stroke är detta fenomen inte robust utan verkar förutsätta snäva dosintervall och/eller andra specifika experimentella förutsättningar. Även om dessa studier är genomförda på gnagare är förhoppningen att de i längden kan bidra till förståelse av när behandling med östrogen ur hälsosynpunkt är positivt, och när det är negativt. Dessutom presenteras verktyg för att forskare inom experimentell strokeforskning ska kunna förbättra kvaliteten på sina studier. 


\section{Background}

In a study from 2005, conducted in our lab, it was found that $17 \beta$-estradiol increased ischemic lesions in rats subjected to focal cerebral ischemia [1]. This finding was highly surprising since most previous studies had demonstrated clear neuroprotective effects of estrogens. An ongoing quest for us has since been to investigate whether differences in $17 \beta$-estradiol plasma concentration and administration methodology between the estrogen-stroke studies might explain the discrepant results. This has also led us to more broadly study methodological aspects of rodent stroke models experimentally and meta-analytically.

The main focus of this thesis is methodology of experimental stroke research with special reference to $17 \beta$-estradiol. The first part of the background is dedicated to describing stroke in general (1.1) as well as animal models of the disease (1.2), followed by presentations of challenges associated with this field and the use of metaanalyses for experimental stroke research (1.3). The last part describes the female sex hormones estrogens and previous knowledge concerning their effects in relation to cerebral ischemia (1.4).

\subsection{Stroke}

The term stroke comprises several conditions, with different pathophysiology and suggested managements. The three most common subcategories are ischemic stroke $(\approx 85 \%)$, intracerebral hemorrhage $(\approx 10 \%)$ and subarachnoid hemorrhage $(\approx 5 \%)$ [2, $3]$, and the focus of this thesis is the first and most common type. Ischemic stroke, or focal cerebral ischemia, refers to the situation when a cerebral blood vessel is occluded and consequently the lack or reduction of oxygen and metabolic substrates will cause ischemic damage in a part of the brain.

\subsubsection{Epidemiology}

Stroke is the second most common cause of death in the world, after ischemic heart disease [3]. However, deaths do not reveal the full burden of this disease since many of those who survive also suffer from chronic sequelae. Worldwide, there were 2.8 million deaths due to acute ischemic stroke in 2010, but 39.4 million disability adjusted life years (DALYs) [4, 5]. In the European Union, it is the number one cause of disability [6]. Approximately 1 million strokes occur in the European Union each year and almost as many in the United States [2,6], a number that is projected to increase considerably due to a growing elderly population [6]. In addition to the consequences for the patient and relatives, the combination of acute management and treatment for long-term complications also makes stroke a major drain on health care funding. Worldwide, it consumes around 2-4\% of total health care costs and an even larger share in the industrialized countries [3]. 


\subsubsection{Clinical presentation}

Clinically, focal cerebral ischemia is most often caused by either in situ thrombosis via local atherosclerosis or an embolus originating from the heart or a proximal large vessel. In addition, a large portion $(\approx 30 \%)$ of strokes remain unexplained despite evaluation [7]. Further, bleeding into the infarction can occur, a phenomenon called hemorrhagic transformation. The most commonly involved vessel in stroke is the middle cerebral artery (MCA), supplying the lateral aspects of the cerebral hemisphere as well as much of the basal ganglia and the internal capsule [7, 8]. However, the presentation can be quite variable depending on the side and location of the occlusion. Typical symptoms are contralateral hemiparesis, sensory loss and facial plegia [8]. Aphasia may occur if the dominant hemisphere (left for right-handed people and also most left-handed) is involved, while e.g. neglect and apraxia can be seen with the non-dominant hemisphere affected [8].

\subsubsection{Pathophysiology}

The pathophysiology of ischemic stroke is complex and several different mechanisms are involved, including excitotoxicity, edema, oxidative stress, inflammation and blood brain barrier (BBB) dysfunction, ultimately resulting in cell death through both necrosis and apoptosis [7, 9-11]. In the situation of ischemia, when a part of the brain is deprived of glucose and oxygen, adenosine triphosphate (ATP) can no longer be produced by the mitochondria and a series of events collectively referred to as the ischemic cascade are initiated. Energy-dependent processes like ion pumps will stop functioning and the resulting depolarization will cause calcium influx. Depolarization will also lead to release of glutamate into the synapses, acting on $\alpha$-amino-3-hydroxyl-5-methyl-4-isoxazole-propionate (AMPA) and especially $\mathrm{N}$-methyl-D-asparate (NMDA) glutamate receptors to cause further flow of $\mathrm{Ca}^{2+}$ as well as $\mathrm{Na}^{+}$and $\mathrm{Cl}^{-}$into the cells, resulting in a vicious circle called excitotoxicity [7, 9]. To maintain osmotic equilibrium, water follows the ion influx causing cytotoxic edema [9], and the calcium excess will also activate calcium-dependent enzymes capable of degrading essential cell components [9]. Further, increased intracellular calcium levels will cause production of free radicals from cell membrane lipids and dysfunctioning mitochondria, damaging cell membranes, proteins, cytoskeleton and deoxyribonucleic acid (DNA) [9, 11]. Release of cytochrome C from mitochondria, as well as reactive oxygen species (ROS) may trigger cell death through apoptosis [11]. Oxidative stress will also contribute to the first phase of BBB dysfunction through activation of matrix metalloproteinases (MMP), whereas the second BBB damage phase (24-72 h) involves leukocyte infiltration and MMP release from neutrophils. As a result of the tissue damage, release of pro-inflammatory mediators and upregulation of adhesion molecules, the post-ischemic inflammation is initiated. Initially, ROS will activate astrocytes capable of increasing the inflammatory response and microglia that can transform into phagocytes and release cytotoxic substances [9]. Other inflammatory cells, including neutrophils, T cells and bloodderived macrophages, also play a role [10]. However, although the early phase of post-ischemic inflammation seems to be predominantly deleterious, most of the cell 
types exert both adverse and beneficial effects [10].

Depending on the extent of collateral circulation, regions of the brain area supplied by the occluded vessel will be affected to varying degrees. In the infarct core, almost no collateral circulation exist and thus the cells will perish within minutes. Surrounding the core is the penumbra, defined as an ischemic but reversibly dysfunctional tissue [7]. Prompt restoration of blood flow can save the penumbra and thus decrease the size of the infarct but reperfusion may also have detrimental effects through reperfusion injury. This is mediated, among other mechanisms, by oxidative stress and inflammation $[9,12]$. If the occlusion remains, infarct core will grow at the cost of the penumbra [12].

\subsubsection{Treatment}

Thrombolysis (tissue plasminogen activator; tPA) is still the only specific pharmacological treatment proven efficacious in acute ischemic stroke [13]. Further, although the evidence for the efficacy of tPA is compelling, the proportion of stroke patients worldwide who receive this treatment is low. Even in high-income countries, only around $7-8 \%$ receive the treatment $[14,15]$. The numbers for many less wealthy countries are largely unknown, but they are likely to be lower [16]. Lack of necessary resources like computed tomography scanners and personnel limit the use of tPA despite the fact that nearly $90 \%$ of all strokes are estimated to occur in low- and middle-income countries [16]. In addition to the sole pharmacological treatment of tPA, two other strategies have proven efficacy. The first one is post-stroke care in "stroke units" [17], probably through prevention of complications [18]. However, although beneficial for patients in high-income countries, this concept is yet to be implemented in many low- and middle-income countries, where resources are scarce [19]. More research is needed to disentangle the multiple effects in order to sort out the most important components that could perhaps be used also in more basic settings [19]. The second strategy, thrombectomy, was earlier questioned but has now been proven beneficial with modern equipment [20]. Moreover, despite the increased knowledge regarding the causative factors of stroke, e.g. smoking and hypertension, many questions remain to be elucidated. Among them is the relation between hormone replacement therapy (HRT) in menopause and stroke, as discussed below.

\subsection{Animal models of cerebral ischemia}

Animal models of cerebral ischemia have been used in research for several decades. Rats and mice are most widely used but other species have also been studied, e.g. cats [21], dogs [22], sheep [23], non-human primates [24] and squirrel monkeys [25]. Several different methods to occlude the blood flow exist and the basic characteristics of the most common are described below (intraluminal filament method, direct mechanical methods, photothrombosis, emboli/clot methods, and various methods to cause global ischemia). 


\subsubsection{Intraluminal filament method}

The intraluminal filament method is the most popular method to occlude the MCA in both rats and mice, and was used for ischemia induction in Paper IV. A detailed description of the procedure is included in Material and Methods (4.2.4.). The basic principle is that a filament, inserted in an extracranial vessel, is advanced up to the MCA to obstruct the blood flow. The method was originally developed by Koizumi et al. [26] in 1986 and further by Longa et al. in 1989 [27]. While Koizumi used siliconecoating, Longa heat-blunted the filament tip. Intraluminal filament occlusion does not require craniotomy and is therefore relatively fast and convenient. Permanent as well as transient (by withdrawing the filament) occlusion of any duration is possible. Among the issues that have been raised regarding this method is that the reperfusion is overly abrupt when removing the filament. This might be a problem if the goal is to mimic a clinical situation of thrombolysis or spontaneous recanalization, occurring gradually $[18,28]$.

\subsubsection{Direct mechanical methods}

The direct occlusion methods require craniotomy to reach the MCA. The principle is very straightforward but demands considerable skills and training for optimal results. Once the vessel is exposed, the blood flow is obstructed by electrocoagulation [29], suture ligation [30] or microclip application [31], with the latter two also allowing controlled reperfusion. An advantage of the craniotomy methods is the ability to visually confirm occlusion and occlusion site, but the procedures are invasive and time-consuming. A similar method that could be included in this group is the endothelin method where occlusion is obtained by injecting the vasoconstrictor endothelin-1 close to the MCA [32]. In addition, a less invasive stereotactic injection of endothelin-1 approach has been attempted [33]. The vasoconstrictive effect of endothelin-1 is dose-dependent but the control over occlusion intensity and duration is limited, compared to e.g. applying and removing a vascular clip.

\subsubsection{Photothrombosis}

Photothrombosis-induced ischemia is produced by intravenously injecting a photosensitizing dye (rose bengal) and subsequently irradiating a cortical area with green light, resulting in massive microvascular coagulation [34]. No craniotomy is required and the infarcted area can be clearly defined. However, a drawback is that the occlusion occurs in many small vessels and therefore differs from the clinical situation of an embolus or a thrombus in a large artery.

\subsubsection{Emboli/clot methods}

The first study using a homologous blood clot to induce cerebral ischemia was described by Kudo et al. in 1982 [35]. The idea is to more closely mimic the clinical situation by obstructing the blood flow with an actual clot, delivered by injection or through a catheter. An important difference in relation to other methods is that thrombolytic therapies can be tested using this model since the occluding material 
is the same as for humans. Disadvantages are that the researcher has limited control over where the clot will eventually lodge and that spontaneous recanalization may occur. A variant of the emboli/clot methods was described by Orset et al. in a study where in situ thrombosis was produced by injecting thrombin directly into the MCA after craniotomy [36].

\subsubsection{Global ischemia}

The models described above represent focal cerebral ischemia, the focus of this thesis, but it should be mentioned that the concept of cerebral ischemia also comprises global ischemia. In humans, this condition develops after cardiac arrest with resuscitation or after near-drowning. The pathophysiology is different from that of focal cerebral ischemia and involves delayed neuronal death and astrogliosis [37]. No ischemic core or penumbra is seen, instead the ischemic damage is determined by specific vulnerability of different cell types in different brain areas [38]. Global ischemia can be induced in rodents by several different techniques, e.g. decapitation [39], neck compression by a pneumatic cuff [40], 4-vessel occlusion (common carotid and vertebral arteries) [41] and 2-vessel occlusion (common carotid arteries in combination with systemic hypotension [42]. The unique vascular anatomy of gerbils, lacking the posterior communicating artery, has been utilized to model global ischemia in this species since bilateral common carotid artery occlusion thus is sufficient [43].

\subsection{Methodological issues in experimental stroke}

Methodology and design of experimental stroke studies have been debated over the last years due to the lack of translational success for stroke treatments. This despite major advances made in the understanding of the pathophysiology of stroke, clarifying the etiology and identifying possible targets. Regarding treatment, much research has focused on neuroprotection, i.e. substances that could interfere with the events of the ischemic cascade (see above) to prevent death of cells in the penumbra [44]. Another approach, as exemplified by Paper IV, is to study how pre-treatment with a substance affect damage outcome. Hundreds of promising candidates have been tested in clinical trials $[13,45,46]$ but as described above, the evidence-based treatment options remain few. This difficulty to transfer results from experimental studies to the clinic (from bench to bedside) has been a discouraging element in the experimental stroke field for years and is often referred to as a "translational roadblock" [13, 45]. The possible reasons behind it, particularly lack of methodological quality of the studies, have been discussed widely (see Figure 1). Although highly topical in the stroke field due to slow therapeutic progress, it should be mentioned that similar quality issues have been discussed also in many other research areas, e.g. cardiology $[47,48]$ and intensive care [49]. A highly accessed article by Ioannidis, published in 2005, made the case that most published research findings in all fields are false [50] and many of the issues that he brings up are relevant for stroke research. 
Regarding study quality, some factors that have been mentioned as possible culprits are weak reporting on exclusion and mortality, lack of randomization and blinding, publication bias and low statistical power (determined by effect size, variability in outcome and sample size) [51]. Low statistical power is the result of high outcome variability and mortality in combination with few animals in the experiments. Although this can theoretically be overcome by increasing the group sizes enough, such a solution has several problematic implications. From an ethical point of view, it is recommended to use as few animals as possible according to the "three $\mathrm{R}$ principle” (replace, reduce, refine: [52]) and working with large number of animals is both practically inconvenient (time and space consuming) and costly. Therefore, as a complement, it would be desirable to have an animal model optimized to minimize unnecessary outcome variability and mortality.

Among other things, Ioannidis [50] (see above) discusses flexibility in design as a problematic factor and this is highly applicable to experimental stroke research. When setting up a rodent stroke study, numerous methodological choices have to be made. Not just what stroke model to use but also regarding e.g. strain, animal age and health status, occlusion duration, infarct measurement procedure, functional tests and post-operative care (see Figure 2 for an overview). The design vary considerably among studies and these decisions will obviously influence the results obtained. Although hundreds of rodent stroke articles are published each year, no consensus exists regarding the ideal methodology. The fact that the possible combinations of methodological parameters are innumerous probably explains why a proper experimental comparison of all the different options has not been performed.

\subsubsection{Systematic reviews and meta-analyses in experimental stroke research}

As abovementioned, it is clear that there are limitations to the translational paradigm for stroke research in its current state. The number of preclinical studies published each year increases, while the proportion of innovations actually reaching the clinic decreases [53]. In addition, the substantial volume of preclinical research available makes it hard for the individual scientist to get a good overview and draw proper conclusions [53]. A systematic review is essentially a way to make objective sense of available data regarding a specific research question by gathering all relevant information in a structured fashion. Such a review may be followed up by a statistical analysis of the data, a meta-analysis, to provide a summarized outcome from several different studies. This distinction between systematic review and meta-analysis was suggested by Chalmers and Altman by the early 1990s to clarify the terminology [54]. In A Dictionary of Epidemiology, the following definitions are given:

"Meta-analysis - A statistical analysis of results from separate studies, examining sources of differences in results among studies, and leading to a quantitative summary of the results if the results are judged sufficiently similar or consistent to support such synthesis" 


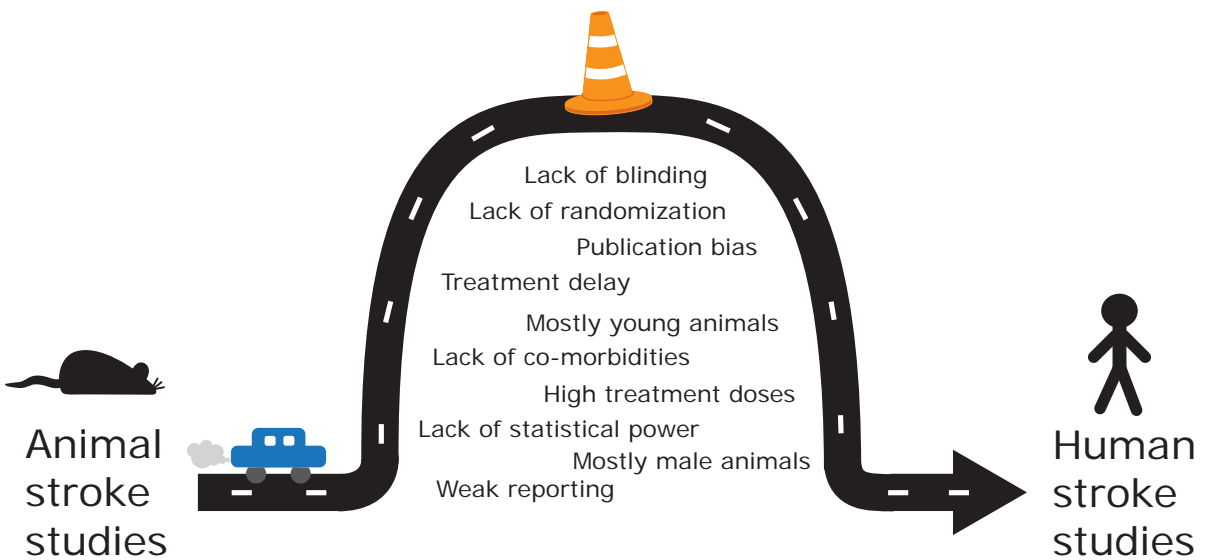

Figure 1. Examples of factors suggested to contribute to the "translational roadblock". The difficulty to transfer results from experimental stroke studies to the clinic has been widely debated in recent years and several issues have been mentioned as possible culprits.

"Systematic review - A review of the scientific evidence which applies strategies that limit bias in the assembly, critical appraisal, and synthesis of all relevant studies on the specific topic"

The first meta-analysis, performed in 1904 by statistician Karl Pearson, investigated inoculation against typhoid fever [55]. However, the term "meta-analysis" was not coined until 1976 when Gene Glass used it to refer to "the statistical analysis of a large collection of analysis results from individual studies for the purpose of integrating the findings" [56]. In clinical medicine, meta-analyses are used routinely, primarily thanks to the Cochrane collaboration which has been instrumental in establishing a framework to gather and analyze information in order to facilitate evidence-based health-care policies and clinical decision making [57].

The use of meta-analyses for preclinical research with laboratory animal experiments is relatively new but has had a remarkable increase in popularity during recent years [58]. In the preclinical stroke field specifically, meta-analyses have exposed flaws associated with preclinical stroke research and fueled the discussion regarding methodological rigor in the field $[46,59,60]$. As such, they have provided several concrete suggestions to possible ways of overcoming the translational difficulties. However, the focus of these studies was treatment effect and how study design and quality affected this rather than the actual impact of methodological parameters on the outcome, independent of treatment effect, as in Papers II and V. To promote and support the use of systematic review and meta-analysis for animal data, initiatives such as the Collaborative Approach to Meta-Analysis and Review of Animal Data from Experimental Studies (CAMARADES) [61] and the SYstematic Review Centre for Laboratory animal Experimentation (SYRCLE) [62] were established. 
CAMARADES is an international network providing a supporting framework for groups involved in the systematic review and meta-analysis of data from experimental animal studies. Originally, the sole focus was stroke research as a response to repeated translational failures but since it was concluded that the issues identified in the stroke field might also be relevant in animal modelling of other diseases, it was decided to change the $\mathrm{S}$ of CAMARADES from "Stroke" to "Studies". SYRCLE is a research environment based in the Netherlands, striving to be a center of expertise in systematic reviews of animal studies and to facilitate efforts towards more evidencebased translational medicine. The use of systematic review is also motivated from an animal ethics point of view. By extracting existing data, available in already published studies but not used for the original analysis, new research questions can be answered without using more animals. In addition, by investigating all the available relevant data simultaneously, firm conclusions can be reached in order to prevent unnecessary replication. Moreover, important research gaps may be identified to guide future research.

Regarding the relation between estrogens and stroke, several clinical meta-analyses have been carried out [63-66]. For animal studies on the subject, the situation is different. Although the narrative reviews are numerous [67-71], the studies actually utilizing a systematic and/or meta-analytical approach are few. To our knowledge, only three such studies exist: one by Gibson et al. from 2006 [72] and two from our lab, Ström et al. from 2009 [73], and Paper III of the current thesis.

\subsection{The effects of estrogens on ischemic stroke}

Linking up with the previous section regarding study design and experimental stroke, an example where the methodology has been suggested to account, at least in part, for contradictory findings is the question regarding the effects of estrogens on stroke. After an introduction to the estrogen family of hormones, a review of their relation to ischemic stroke will follow.

\subsubsection{Estrogens}

The first hormone of the estrogen family to be isolated was estrone, done independently by Butenandt and Doisy in 1929 [74]. However, the most potent naturally occurring estrogen is $17 \beta$-estradiol, followed by estrone and then estriol. Estrogens, like all other steroid hormones, are synthesized from cholesterol and each contains a phenolic A ring which is crucial for selective high-affinity binding to the receptors. The A ring is aromatized when androstenedione and testosterone are turned into estrogens, a reaction catalyzed by the enzyme aromatase [75]. Clinically, the two major uses of estrogens are as components of combination contraceptives and in HRT to treat postmenopausal symptoms such as hot flashes, night sweats, and vaginal dryness and atrophy [76].

In premenopausal women, estrogens are mainly produced in the ovaries. The theca 


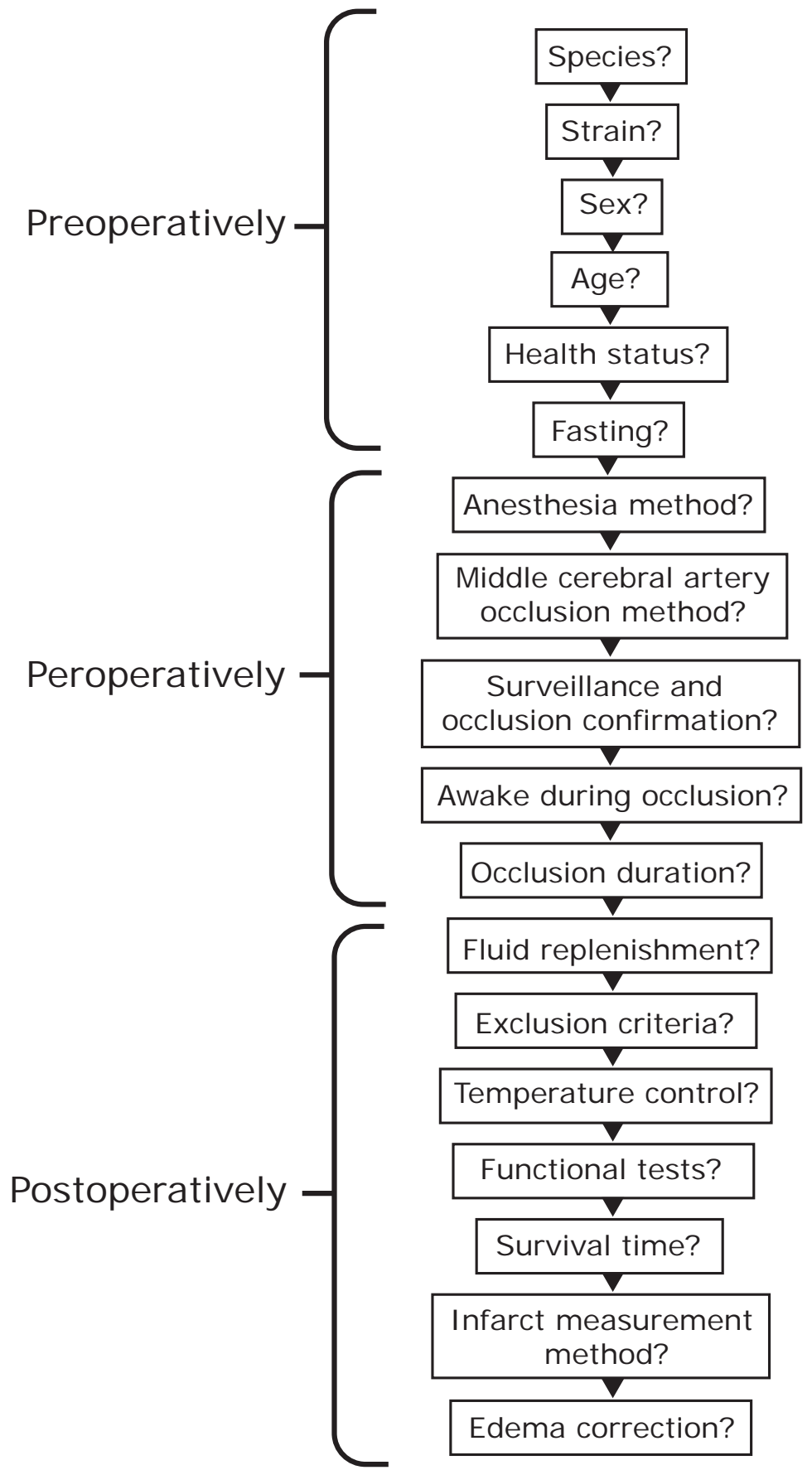

Figure 2. Examples of methodological choices when designing a rodent stroke experiment. Hundreds of articles are published each year but no consensus exists regarding the ideal design. The fact that the possible combinations are innumerous probably explains why a proper experimental comparison of all the different options has not been performed. 
cells express the enzymes necessary to convert cholesterol to androgens but lack the enzymes to convert the androgens to estrogens, a task fulfilled by the granulosa cells. These cells are regulated by the gonadotropins follicle-stimulating hormone (FSH) and luteinizing hormone (LH) from the gonadotropic cells in the anterior pituitary, in turn controlled by the gonadotropin-releasing hormone ( $\mathrm{GnRH})$ of hypothalamic origin. $17 \beta$-estradiol circulates in the blood in three different forms: $2-3 \%$ free and biologically active, $60 \%$ weakly bound to albumin and the remaining $38 \%$ bound with high affinity to the glycoprotein sex hormone-binding globulin (SHBG) [77]. It is mainly metabolized in the liver by sulfation or glucuronidation, and the conjugates are excreted into the bile or urine [78]. This circulating portion dominates, but local production e.g. in the central nervous system through aromatization of androgens also contributes to the overall estrogenic effects in the body [75]. In men, lower levels of estrogens are produced by the testes to a small extent, but primarily through extragonadal conversion of androgens.

The menstrual cycle consists of two main phases, the follicular phase and the luteal phase. The follicular phase starts on day 1 of the cycle, when the menses begin, and during this part of the cycle a single mature oocyte is produced every month from puberty to menopause. The follicular development will select the maturing follicle most responsive to FSH while the rest of the germ cells present from development are destined to undergo apoptosis, a few every month [79]. After ovulation, the remnants of the ruptured follicle will become the corpus luteum, regulated by LH. If no fertilization takes place, and hence no placenta is created to support the corpus luteum, it will stop secreting hormones and degenerate into a scar tissue called corpus albicans [79]. The cycle starts over again by shedding of the uterine endometrium that has proliferated during the cycle. The estrogen levels are low during the follicular phase, with a transient peak before ovulation and a smaller rise during the luteal phase. Throughout the cycle, estrogens primarily exert negative feedback on the release of LH and FSH, but a brief positive feedback actually exists mid-cycle where high levels of estrogens trigger the surge of LH which stimulates ovulation 24-36 hours later [79].

Rodents, like women, have naturally occurring variations in estrogen concentration throughout the ovarian cycle. However, whereas women have a menstrual cycle lasting about 28 days, rodents have a 3-6 day estrous cycle, often divided into three phases; pro-estrus, estrus and diestrus [80, 81]. Rats typically begin cycling between postnatal days 32 and 36, immediately after the vaginal orifice opens [82]. In mice, the estrous cycle is similar to that in rats with a few exceptions: several days or weeks may pass between vaginal opening and the first ovulation, irregularities are more common, and the cyclicity is more easily influenced by environmental conditions [82].

With age, accelerated follicular apoptosis, and eventually depletion of all of the oocytes, the menopause occurs for women. This process that takes place over 
several years, often with gradually disappearing cyclicity. As a result of the loss of ovarian function, the circulatory levels of estrogens decrease by approximately $90 \%$, and the primary source of estrogens will be the adrenal glands, secreting dehydroepiandrosterone that can be converted to estrone in adipose tissue stroma [79]. Some estradiol is also formed by extragonadal conversion of testosterone. This extragonadal estrogen synthesis increases as a function of age and body weight [79].

In rats and mice, the corresponding event occurs around 6-18 months with increasingly abnormal gonadotropin release patterns [83, 84]. After a period of lengthening of the cycle, a constant acyclic state of vaginal cornification can be observed, called "persistent estrus". This phase is characterized by polyfollicular ovaries and moderate levels of estrogens. There is still some maturation of follicles, and subsequent atresia without ovulation, culminating in complete follicular depletion. Eventually, rodents will enter the final stage of reproductive senescense termed "persistent diestrus" or "persistent anestrus" with estrogen levels comparable to those among ovariectomized rodents.

The physiological actions of estrogens are many and widespread. In addition to the effects directly related to reproduction (see above), several other organs are targeted. Growth and differentiation of breasts are stimulated, in bones the overall effect is antiresorptive and in the liver the expression of proteins related to lipid metabolism and hemostasis are regulated [85]. A vast variety of functions of the nervous system are also influenced by estrogens, including but not limited to, learning, memory, mood and behavior, neurogenesis and neuronal protection [86] (see 1.4. for more on the effects of estrogens in relation to ischemic stroke). In addition to the estrogens, other compounds e.g. flavones and isoflavones occurring in plants and fungi, have estrogenic and anti-estrogenic activity [75].

Estrogens act mainly through interaction with estrogen receptors (ERs), belonging to the superfamily of nuclear receptors. The first evidence for the existence of nuclear receptors actually came from work with $17 \beta$-estradiol, when Jensen et al in 1961 found that it forms a complex in the nucleus with a protein [87]. The second receptor was cloned by Swedish researchers at the Karolinska Institute in 1996 [88], and this was termed ER $\beta$ to distinguish it from the receptor identified by Jensen, termed ER $\alpha$. The two estrogen receptor genes are located on separate chromosomes: ESR1 encodes $E R \alpha$, and ESR2 encodes ER $\beta$. The expression of ER $\alpha$ and ER $\beta$ differs in some ways, but there is overlap. In some organs the levels are similar, in others one or the other subtype predominates. ER $\alpha$ expression is mainly in the uterus, prostate, ovary, testis, epididymis, bone, breast, liver, kidney, adipose tissue and various regions of the brain [86] whereas ER $\beta$ is predominantly expressed in the colon, prostate, testis, ovary, bone marrow, salivary gland, vascular endothelium, lung, bladder and some regions of the brain [86]. After diffusing through the cell membrane, the hormone binds to an ER, mostly nuclear but also found in the cytoplasm. Receptors dimerize to homo- and heterodimers and bind to estrogen responsive elements to modulate gene 
transcription [79]. Ligands that act specifically on ER $\alpha$ (PPT and MPP) or ER $\beta$ (DPN and R,R-THC) are available for research purposes, but have not reached clinical use $[75,89]$. In more recent years, it has also been found that estrogens can have nongenomic rapid onset effects. These are mediated by second-messenger-linked ER $\alpha$ and ER $\beta$ localized on the cell membrane, or by a receptor that is genetically and structurally unrelated to ERs called G-protein coupled estrogen receptor 1 (GPER, formerly referred to as G-protein coupled receptor 30) [86]. However, much is still unknown regarding the role of these fast-acting receptors.

\subsubsection{Estrogens and cerebral ischemia}

Premenopausal women have a lower risk of stroke than men of the same age, and the incidence of stroke in women increases after menopause, coincident with diminished circulating levels of estrogens [90]. On account of these facts, a common hypothesis among researchers has long been that female sex hormones, especially estrogens, provide protection against cerebrovascular events. Further, in animal models of cerebral ischemia, several studies in the 1990's demonstrated neuroprotective effects of estrogens [91-93]. The idea of a beneficial effect on the brain was also supported by epidemiological studies showing that estrogens given as postmenopausal HRT decreased the risk of stroke $[94,95]$. However, the large Women's Health Initiative (WHI) study [96] meant a major turning point in that it reported the opposite, increased risk of cardiovascular diseases including stroke with HRT, and prescription was dramatically reduced as a consequence [76]. Moreover, the unexpected results from WHI stimulated a heightened interest in the diverse effects of extrogens in various tissues throughout the body. To illustrate this, Gillies et al. measured the number of published studies into the estrogen actions in the brain alone and found an average of almost two publications a day [76].

Interestingly, discrepancies similar to those for the clinical situation exist also in the animal literature. As abovementioned, the earliest rodent studies on the effects of estrogens on ischemic stroke showed protective effects, and the vast majority of the later studies also corroborated this (e.g. [97-99]). However, there are also several examples of estrogen-stroke studies where detrimental effects of the hormone have been demonstrated [1, 100-102].

Several suggestions have been put forth as to why the results differ, in animals and humans alike. Perhaps the theory that has received the most attention is referred to as the "timing hypothesis" (or the window of opportunity hypothesis). This theory states that estrogens must be administered shortly after menopause (or ovariectomy/ oophorectomy) to have beneficial effects, and stems from the fact that the mean age in the WHI study was 63, approximately 10 years older than the age when most women enter menopause and thus usually are treated for perimenopausal symptoms. However, further analyzed data from the WHI provide little support for the hypothesis of favorable effects among women who initiate HRT soon after menopause [103]. There are also some animal data in favor of this hypothesis, showing that animals 
who have experienced a period hypoestrogenicity do not have the same protective effects of estrogen treatment [104]. An idea related to the timing hypothesis is that high age is the critical factor rendering estrogens toxic instead of beneficial [71, 105]. The majority of the animal studies have used young adult rodents whereas the clinical trials naturally included older menopausal women. Other hypotheses aiming to explain the differences in animal studies concern e.g. strains [106] and the presence of comorbidity [107]. Although very briefly, estrogen dose (one of the issues addressed in the current thesis) has also been discussed by researchers outside our group [71, 101].

Our hypothesis that estrogens' effects on ischemic are dose-dependent originates from the rat study showing increased damage after estrogen treatment that was performed in our lab [1]. When the administration method (slow-release pellets) used in that study was investigated, it was found that very high concentrations were produced [108-110]. In fact, when the estrogen-stroke study was repeated, only with a different administration method (silastic capsules), protection was seen [31]. These silastic capsules were in the abovementioned administration studies shown to produce lower and more stable hormone concentrations than the slow-release pellets. Further, in a systematic analysis of all studies on the effects of estrogens on cerebral ischemia in rats it was found that the slow-release pellets had been used in all studies showing detrimental effects [73].

Regarding the mechanisms, numerous explanations have been proposed. Most of them are focusing on protection but there are also some possible harmful pathways. As explained in 1.1., oxidative stress plays an important role in the ischemic cascade when the cells' own defense systems are insufficient to cope with the massive production of reactive oxygen species. This is one of the pathways that estrogens have been shown to interact with, both positively and negatively. For example, through radical scavenging [111] and reducing lipid peroxidation [112], the neuronal damage is attenuated. Conversely, estrogens have also been demonstrated to exert pro-oxidant actions and thereby possibly augment ischemic damage [113]. Inflammation is a component of many brain pathologies, including stroke, and this is another pathway where paradoxical effects of estrogens have been observed. Predominantely, the effects seem to be anti-inflammatory e.g. by reducing pro-inflammatory cytokine synthesis [114] and leukocyte adhesion [115], but signs of increased inflammation exist in certain situations [116]. Examples of other reported protective mechanisms are anti-apoptosis [117], growth-factor regulation [118] and enhanced neurogenesis in the subventricular zone [119]. Other possible detrimental mechanisms that have been discussed are increased excitotoxicity $[120,121]$ and influence of animal weight $[101,122]$. The rationale behind the possible relation between weight and damage severity is the so called "obesity paradox" which states that although obesity might increase the risk of stroke, patients with mild obesity actually seem to have a better outcome [123]. Theoretically, weight loss in rats treated with estrogens in high doses could therefore counteract possible protective effects and the resulting outcome be 
increased damage.

Both ER $\alpha$ and ER $\beta$ are expressed in the brain, as mentioned in section 1.4.1., and it is not clear which receptor mediates the effects of estrogens in relation to cerebral ischemia. Most animal studies suggest that ER $\alpha$ is the critical subtype for neuroprotection $[121,124,125]$ but others claim that ER $\beta$ is important as well [126, 127].

\subsubsection{The concept of hormesis}

One of the hypotheses of this thesis is that estrogens can be both neuroprotective and neurodamaging depending on treatment dose. The phenomenon behind this hypothesis, that a substance might exert dose-dependent, diametrically different effects, is reflected in the concept of hormesis (Greek for "rapid motion”, "eagerness"). The term hormesis was originally used in 1943 by Southam and Ehrlich, in an article describing that high concentrations of an anti-fungal agent decreased fungus growth, while low doses actually stimulated it [128]. However, the basic idea has been around for much longer and some aspects of it are covered by the old well-known Paracelsus quote "All things are poison and nothing is without poison; only the dose makes a thing not a poison". Several other terms for similar phenomena have been used, e.g. "biphasic", "bidirectional", "U-shaped" and "inverted U-shaped" dose response curves, and the exact definition of hormesis has been debated [129, 130]. Perhaps the most influential and passionate advocate of the concept is the American toxicologist Edward Calabrese, who claims that hormesis is the fundamental dose-response model [131].

In section 1.4.1. it was described that estrogens can act in a variety of ways: via two different nuclear receptors affecting gene expression as well as through interaction with receptors on the cell membrane mediating more rapid actions. Considering this, it is not unexpected that estrogens could act in a hormetic fashion, with different pathways predominating at different concentrations. There are indeed several examples of estrogenic hormesis, e.g. regarding bone development, plasminogen activator regulation, and growth of cultured tumor cells [132]. 


\section{Hypothesis}

Two main hypotheses are investigated in this thesis. Firstly, that discrepant findings regarding estrogens' effects on cerebral ischemia might be explained by differences in methodology, especially mode of $17 \beta$-estradiol administration resulting in different serum concentrations. Secondly, that certain methodological choices in experimental stroke studies will affect outcome variability and mortality. 


\section{Aims}

- To evaluate the commonly used subcutaneous methods for long-term $17 \beta$-estradiol administration to mice, and to develop and characterize a novel peroral method.

- $\quad$ To investigate the impact of different methodological parameters on the effect of $17 \beta$-estradiol in rat stroke models.

- To analyze how methodological choices in rodent stroke studies affect outcome variability and mortality.

- $\quad$ To test the effects of different doses of $17 \beta$-estradiol on focal cerebral ischemia in rats. 


\section{Material and Methods}

\subsection{Overview of study designs}

For a simplified overview of the studies included in the thesis, please also see Figure 3.

The objective of Paper I was to compare $17 \beta$-estradiol concentrations achieved by two commonly used methods for long-term $17 \beta$-estradiol administration to ovariectomized female mice (subcutaneous silastic capsules and slow-release pellets) during five weeks. We also characterized, both in short- and long-term perspective, a novel peroral method with $17 \beta$-estradiol administered in the hazelnut/chocolate spread Nutella ${ }^{\circledR}$. In addition, the effect of a two-week washout period before hormone administration was evaluated.

Papers II and V aimed to investigate the impact of method parameters on mortality and infarct size variability in experimental stroke studies on rats and mice, respectively. Data were extracted from previously published articles and meta-analyzed using multiple linear regression.

Also in Paper III a meta-analytical approach with multiple linear regression was employed to study the role of method parameters in previously published rat stroke studies. However, in this paper the goal was to investigate how these factors affected the impact of estrogens on infarct size.

In Paper IV, the effects of high and low $17 \beta$-estradiol doses on focal cerebral ischemia in rats were tested. Ovariectomized rats were administered hormone via subcutaneous silastic capsules for two weeks before subjected to 30 minutes of middle cerebral artery occlusion using the intraluminal filament method. Blood samples were obtained on days 2, 7 and 14 to measure concentrations of 17 $\beta$-estradiol. Another group of rats were administered high-dose $17 \beta$-estradiol slow-release pellets and blood sampled to enable comparison of obtained $17 \beta$-estradiol levels between the capsules and the pellets. 

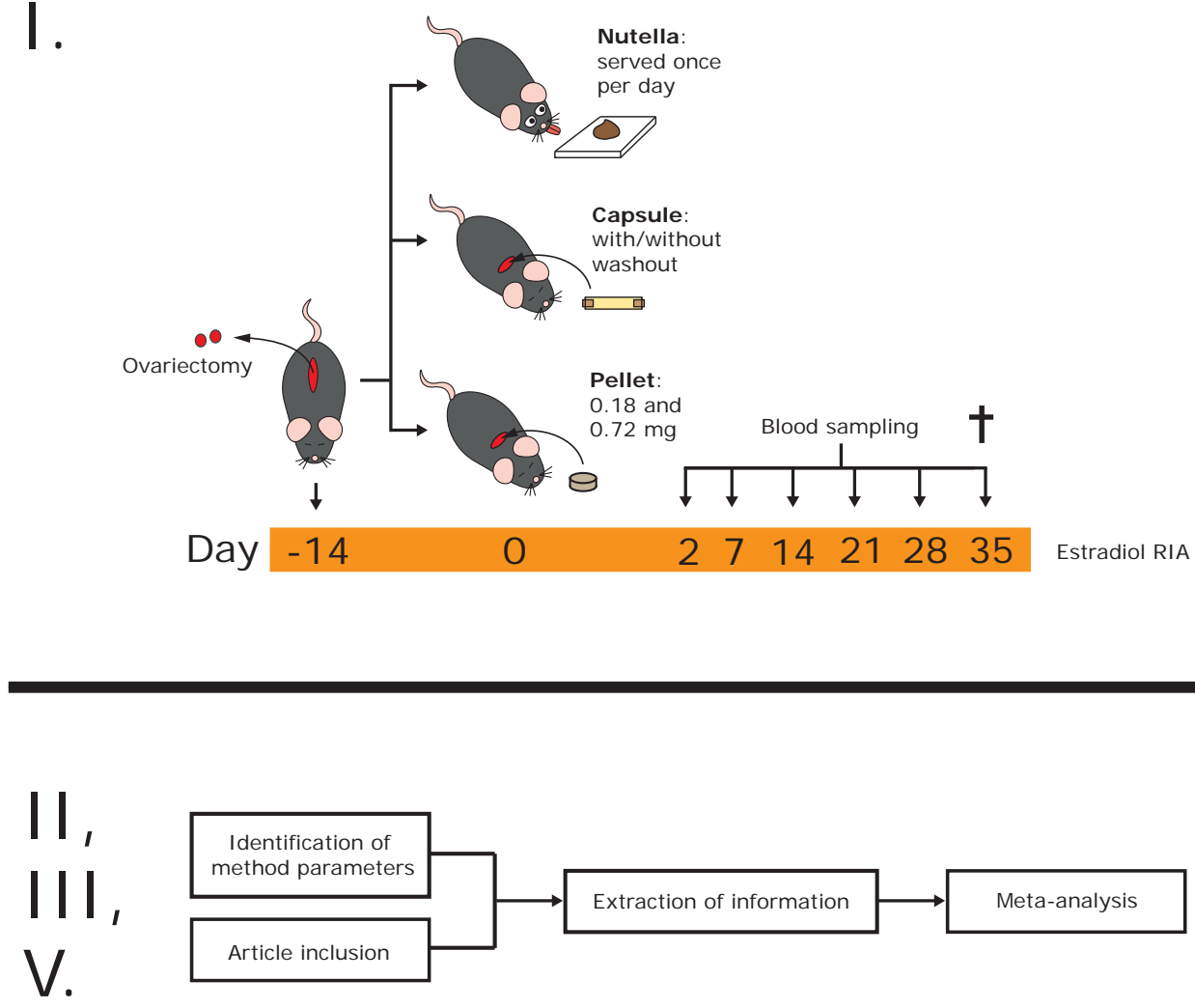

Extraction of information

Meta-analysis

IV.

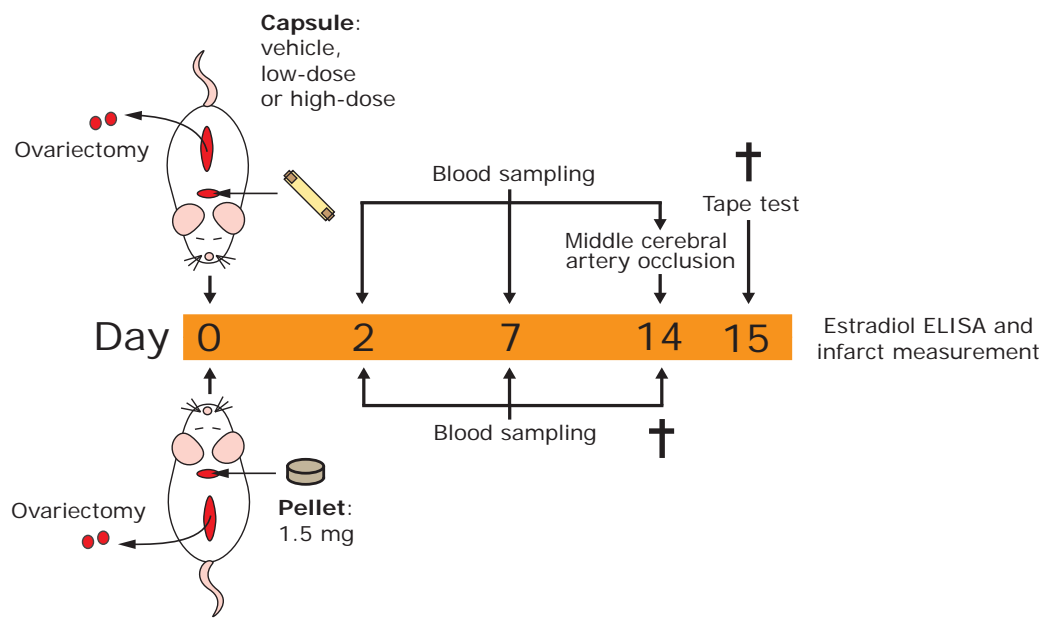

Figure 3. Overview of study designs for the papers included in the thesis. 


\subsection{Experimental studies (Papers I and IV)}

\subsubsection{Animals}

Rodents are often used in animal models of ischemic stroke. Rats have been the most popular choice but the available transgenic opportunities with mice have increased their popularity. Both rats and mice are relatively small, easily handled and have a short generation time. The mouse strain in Paper I, C57BL6, is the most widely used inbred strain (https://www.jax.org/strain/000664, accessed 2015-10-05) and was therefore considered suitable for a study with the goal of establishing a protocol for other researchers to adopt in their experiments. For Paper IV outbred albino Wistar rats were used, and this strain is very common in rat stroke experiments (second only to Sprague Dawley among the 304 studies included in Paper II [133]). We have previously worked with Sprague Dawley rats (another outbred albino strain) in our lab but switched to Wistar in an effort to try to reduce infarct size variability [133, 134]. Both Papers I and IV have a bearing on the clinical issue of hormone replacement therapy for menopausal women, why female animal models were considered more relevant.

For the studies including original animal experiments (Papers I and IV), all procedures were conducted in accordance with the National Committee for Animal Research in Sweden and Principles of Laboratory Animal Care (NIH publication no. 86-23, revised 1985). The protocols were approved by the Local Ethics Committee for Animal Care and Use at Linkoping University. In total, 319 animals were used in Papers I and IV; 189 C57BL6 mice in Paper I and 130 Wistar rats in Paper IV. For Papers II, III and V no new animals were used; all data were obtained from previous experiments conducted in other labs (10701 animals in total; 4531 rats in Paper II, 1979 rats in Paper III and 4191 mice in paper V).

\subsubsection{Ovariectomy and $17 \beta$-estradiol administration}

In estrogen research using rodents, it is common practice to ablate the main source of estrogens by ovariectomy and subsequently administer exogenous $17 \beta$-estradiol. The goal of this procedure is to achieve stable physiological or pharmacological $17 \beta$-estradiol concentrations without the cyclicity. Several different methods have been described but consensus is lacking regarding the optimal procedure. Preferably, an administration method should be cheap, convenient and standardized. Further, since the pharmacokinetics differ between continuous and intermittent administration and between different routes e.g. oral and subcutaneous, similarity to the corresponding clinical situation should also be considered.

\subsubsection{Ovariectomy}

On the rats and mice in Paper I (except native controls) and Paper IV, ovariectomies were performed via the dorsal route. The anesthetized animal was put in prone position, and a 1.5/3 (mouse/rat) cm dorsal midline insicion was made cephally, starting from the level of the iliac crest. The skin was bluntly dissected from the 
underlying fascia, after which the fascia was incised, creating two $0.5 / 1 \mathrm{~cm}$ long apertures on each side of the spine, $0.5 / 1 \mathrm{~cm}$ from the midline. Subsequently, the abdominal cavity was reached via careful blunt dissection under the fascia, revealing the adipose tissue in which the ovary was embedded. The ovary was gently pulled out, ligated and cut, and the stump was put back into the abdominal cavity. The same procedure was performed for the contralateral fascia aperture. Finally the fascia incisions and skin wound were closed by 4-0 vicryl sutures.

\subsubsection{Slow-release pellets}

The slow-release pellets ( $3 \mathrm{~mm}$ in diameter) used in Paper I were produced by the company Innovative Research of America (IRA, Sarasota, FL 34236, USA), and contained the active product $17 \beta$-estradiol fused with a matrix (cholesterol, cellulose, lactose, phosphates and stearates; http://www.innovrsrch.com/faq.asp\#M2, accessed 2015-10-09). This kind of pellet has been used in numerous in animal experiments [135-138] and has the advantages that it is produced by only one company and therefore standardized, easy to use and only requires one-time handling of the animal. The manufacturer claims that the pellets release a constant, even amount of active product, and that the active product begins releasing immediately after implantation. The pellets are administered by implanting them in the subcutis. For this, the anesthetized animal is put in prone position and a $0.5 / 1 \mathrm{~cm}$ (mouse/rat) incision is made in the loose skin of the mouse's/rat's neck. After a pocket has been bluntly dissected caudolaterally, the pellet is gently installed using tweezers and the incision is closed.

Three different types of IRA pellets were used for this thesis, two in Paper I and one in Paper IV. The pellets in Paper I were $0.18 \mathrm{mg} / 60$-day release and $0.72 \mathrm{mg} / 90$ day release (SE-121 and NE-121; designed to release $3 \mu \mathrm{g}$ and $8 \mu \mathrm{g}$ each day, respectively). These doses were chosen since they are frequently used and have been claimed to establish physiological concentrations of $17 \beta$-estradiol in mice [136, 137, 139-141]. Also, they differed both in dose and release time and would therefore more broadly demonstrate the performance of the slow-release pellet system. In Paper IV, a $1.5 \mathrm{mg} / 90$-day release pellet (E-121, designed to release $16.7 \mu$ g each day) was used. That pellet increased ischemic damage in a previous study in our lab [1] and was used in Paper IV to enable comparison with high-dose silastic capsules designed to produce similar $17 \beta$-estradiol.

\subsubsection{Silastic capsules}

Silastic capsules for hormone administration are well-used, both for rats [142, 143] and mice $[144,145]$, and they have several benefits. Like the slow-release pellets, they only require one-time handling of the animal. In addition, the capsules are cheap. Since they are home-made, the possible alternatives are countless (e.g. regarding length and width, sealing and hormone concentration) which makes them easy to modify and adapt to the specific needs of a study but also demand that the detailed capsule design is described in articles. 
The capsules used in Papers I and IV were assembled based on the description by Dubal et al. [97], in the same way as those used in previous rat studies from our lab $[31,109,110]$. In paper IV, $30 \mathrm{~mm}$ segments of silastic tubing (inner/outer diameter: 1.575/3.175 mm, Dow Corning, VWR International, Buffalo Grove, IL, USA) were filled with 17ß-estradiol (Sigma-Aldrich Sweden AB, CAS\# 50-28-2, Stockholm, Sweden) dissolved in sesame oil (Sigma-Aldrich Sweden AB, CAS\#8008-74-0, Stockholm, Sweden) and capped with $5 \mathrm{~mm}$ pieces of wooden applicator sticks (birch, length $15 \mathrm{~cm}$, diameter $2 \mathrm{~mm}$, SelefaTrade AB, Spånga, Sweden). The capsules were placed in two subcutaneous pockets dissected caudally in the loose skin of the rat's neck, one on each side. The vehicle group received two vehicle capsules (only sesame oil), the low-dose group received one vehicle capsule and one $180 \mu \mathrm{g} / \mathrm{mL}$ capsule, and the high-dose group received two $50000 \mu \mathrm{g} / \mathrm{mL}$ capsules. The doses were chosen based on earlier results from our lab; the lower dose has previously been neuroprotective [31] whereas the high-dose regimen has been shown to produce levels of $17 \beta$-estradiol higher than or equivalent to the neurotoxic slowrelease pellets (unpublished pilot study and [1]). Since mice were used in Paper I, the size of the capsules was adjusted. Tubing segments of $20 \mathrm{~mm}$ and $3 \mathrm{~mm}$ wooden caps were used, providing a $14 \mathrm{~mm}$ column of vehicle/hormone solution. The mice received one capsule each, filled with $17 \beta$-estradiol dissolved in sesame oil (36 $\mu \mathrm{g}$ $17 \beta$-estradiol $/ \mathrm{mL}$; dose based on an unpublished pilot study). The capsules were stored in the same solution as inside the capsules (overnight in Paper I and for 1-4 hours in Paper IV). The capsules were carefully wiped before inserted. Similarly to the pellet implantation procedure, the capsules were placed in subcutaneous pockets dissected caudally in the loose skin of the neck of the animals.

\subsubsection{Peroral administration}

Since estrogens are usually administered per os to humans, an animal model where the hormone is delivered by this route would, for pharmacokinetic reasons, be an attractive option in studies aiming to mimic the clinical situation. We therefore decided to include a peroral administration method in Paper I, with 17ß-estradiol was delivered in the hazelnut/chocolate spread Nutella ${ }^{\circledR}$ (Nutella; Ferrero Scandinavia AB, Malmö, Sweden). Nutella as a medium for peroral administration to mice has previously been used to administer buprenorphine [146], but its use with $17 \beta$-estradiol had not been reported. During administration, the mice were kept one in each cage and were served $60 \mathrm{mg}$ Nutella, containing $1.12 \mu \mathrm{g} 17 \beta$-estradiol (dose based on an unpublished pilot study), on ceramic tiles $(5 \mathrm{x} 5 \mathrm{~cm}$ ) between 8 a.m. and 12 a.m. daily. The $17 \beta$-estradiol was dissolved in sesame oil before being added to the Nutella cream, so that each $60 \mathrm{mg}$ portion contained $0.312 \mu \mathrm{L}$ of sesame oil. The animals were familiarized by being given $60 \mathrm{mg}$ Nutella without the $17 \beta$-estradiol once a day for four days prior to day 0 . Once fully habituated to the Nutella mixture, all animals consumed the entire portion within two minutes. 


\subsubsection{Blood sampling}

Blood samples were obtained for hormone analyses in Papers I and IV. In Paper I, blood was collected from the mice by submandibular venipuncture using a lancet (Golden Rod Animal Lancet, point length 4 mm; MEDIpoint, Inc., Mineola, NY, USA) into serum tubes (Vacuette ${ }^{\circledR}$ Serum Tubes; Hettich Labinstrument AB, Sollentuna, Sweden) except on the day of sacrifice, when cardiac puncture was used. Venipuncture of the hindleg was used for blood sampling in Paper IV. The rat was anesthetized and put in prone position, the leg was shaved and an elastic band was tied around the extremity as a tourniquet in order to visualize the saphenous vein. Blood was drawn using a $1 \mathrm{~mL}$ syringe (BD Plastipak ${ }^{\circledR}$, Becton Dickinson SA, Madrid, Spain) fitted with a 23 gauge needle (Sterican ${ }^{\circledR}$, Braun Medical AG, Emmenbrücke, Switzerland) and put in a serum tube. Trunk blood was collected at decapitation into $10 \mathrm{~mL}$ laboratory plastic tubes. All blood samples were centrifuged and stored in $-20^{\circ} \mathrm{C}$ until analysis.

\subsubsection{Middle cerebral artery occlusion}

There are many ways to obstruct the blood flow to the MCA and consequently induce focal cerebral ischemia (1.2.). The intraluminal filament method is the most common and was used in Paper IV. Left-sided, 30 minute transient MCA occlusion (MCAo) was performed based on the descriptions by Koizumi [26] and Longa [27]. A $2 \mathrm{~cm}$ cervical midline incision was made and the common (CCA), internal (ICA), and external (ECA) carotid arteries were freed from surrounding tissue. After ligation of the CCA and the ECA, the ICA was temporarily clipped ( $8 \mathrm{~mm}$ artery clip, Rebstock Instruments Gmbh, Dürbheim, Germany). Thereafter, a $30 \mathrm{~mm}$ silicone coated 4-0 nylon suture (403756, Doccol, Redlands, CA, USA) was inserted in the CCA and advanced up the ICA approximately $18-20 \mathrm{~mm}$. After 30 minutes of occlusion (rat kept anesthetized), the filament was withdrawn and the ICA was permanently ligated. Postoperatively, the rats were allowed to recover in a heated cage $\left(30^{\circ} \mathrm{C}\right)$ for 15 minutes and to facilitate eating, water-soaked food pellets were provided in a petri dish on the cage floor. Before MCAo, $5 \mathrm{~mL}$ saline was given as fluid replenishment.

\subsubsection{Anesthetics, analgesics and surveillance}

It is important to minimize the animals' suffering during and after surgical procedures. This is mainly motivated by ethical reasons, but the resulting stress might also have scientific implications by altering behavior [147].

\subsubsection{Anesthesia and analgesics}

During ovariectomy, hormone administration, venipuncture, and MCAo, the animals were anesthetized with isoflurane (1.4-1.5\% maintenance/4.2-4.5\% induction; Forene ${ }^{\circledR}$ inhal-v 250 mL; Abbot Laboratories, Abbot Park, IL, USA) in an oxygen/ nitrous oxide mixture (30\%/70\%). For all procedures with anesthetized animals, ophthalmic ointment (Lubrithal ${ }^{\circledR} 15$ g, Leo Laboratories Ltd., Dublin, Ireland) was provided for eye protection. Three different substances were used for pain relief: the 
non-steroidal anti-inflammatory drug carpofen, the amide local anesthetic bupivacaine and paracetamol (acetaminophen). In Paper I, the animals were injected $5 \mathrm{mg} / \mathrm{kg}$ body weight carpofen (Rimadyl ${ }^{\circledR}, 50 \mathrm{mg} / \mathrm{mL}$; Pfizer, Dundee, Scotland) dissolved in saline subcutaneously in the neck during ovariectomy. In Paper IV, carpofen $5 \mathrm{mg} / \mathrm{kg}$ body weight subcutaneously was used for ovariectomy pain relief. Before MCAo, animals were administered $1.25 \mathrm{mg} / \mathrm{kg}$ bodyweight bupivacaine (Marcain $^{\circledR}$, AstraZeneca, Södertälje, Sweden) subcutaneously, in addition to flavored paracetamol (Paracetamol Apofri, Apofri AB, Danderyd, Sweden) provided at a concentration of $1 \mathrm{mg} / \mathrm{mL}$ in the drinking water two days before MCAo for habituation and until sacrifice.

\subsubsection{Physiological parameters}

In both Papers I and IV, animal body temperature was maintained at $37^{\circ} \mathrm{C}$ with a heating pad coupled to a rectal thermometer feedback system. Further, in Paper IV, oxygen saturation, respiratory rate, and heart rate were recorded by pulse oximetry (SLS-MO-00404, MouseOx, Allison Park, PA, USA).

\subsubsection{Laser Doppler flowmetry}

Laser Doppler flowmetry (LDF; moorVMS-LDF, Moor Instruments, Axminster, Devon, UK) of left hemisphere perfusion was used to confirm correct filament placement based on the technique described by Farr and Trueman [148]. The area between the eye and the ear was shaved and cleaned with Iodopax and an approximately $1 \mathrm{~cm}$ ventral/dorsal incision was made. Avoiding tearing or cutting of nerves, the connective tissue was dissected and, using a pink needle (1.20 mm/18 G diameter), a small hole was made in the temporal muscle. The LDF probe was subsequently poked through the hole and placed against the skull. Finally, while pressing the LDF probe to the skull, the rat was carefully inverted to supine position and the probe was secured with adhesive tape.

\subsubsection{Outcome measures}

\subsubsection{17 $\beta$-estradiol measurement with radioimmunoassay}

Analyses of $17 \beta$-estradiol in rodent blood samples are frequently performed using radioimmunoassay (RIA) since this method is sensitive enough to detect the often very low serum levels [149]. After preincubation of the samples with antiserum, radioactively labeled substance is added that competes for anibody sites with the substance in the samples. A precipitating solution is then added that will bind up the antibodies which in turn are bound to either the substance in the samples or labeled substance. Since the same amount of labeled substance is added to each tube, it is the concentration of substance in the samples that will determine how much of the antiserum will bind to the labeled or unlabeled substance, respectively. The samples are centrifuged and the supernatant is decanted, leaving only the molecules, labeled or unlabeled, that were bound up by antiserum and hence also the precipitating solution, in the pellet. Radioactivity in the pellet is measured using a gamma counter. High radioactivity corresponds to low level of substance in the sample since, in that case, 
much of the labeled substance has been bound up by antiserum in the competition and thus remains in the pellet. Radioactivity in the sample tubes is compared with a standard curve produced in the same analysis using known concentrations of the substance.

The serum samples in Paper I were analyzed with an $\mathrm{I}^{125}$ radioimmunoassay kit (17 $\beta$-estradiol double antibody, KE2D; Siemens Healthcare Diagnostics Inc., Tarrytown, NY, USA) and measured for $1000 \mathrm{~s}$ in a gamma counter (2470 WIZARD $^{2}$ Automatic Gamma Counter; PerkinElmer, Waltham, MA, USA). According to the manufacturer, this method has a lowest detectable concentration of $1.4 \mathrm{pg} / \mathrm{mL}$ and intra- and interassay coefficients of variation of $4-14 \%$ and 3.5-5.5\%, respectively, depending on the concentration. All kits used were of the same LOT number and the reagents were pooled to avoid inter-assay variation. The standard curve and all samples ( $25 \mu \mathrm{L} /$ tube) were analyzed in triplicate and duplicate, respectively.

4.2.6.2. 17ß-estradiol measurement with enzyme-linked immunosorbent assay Enzyme-linked immunosorbent assay (ELISA) was used in Paper IV instead of the RIA kit that we used in previous studies from our lab, including Paper I. The reason for changing method was that the RIA kit was discontinued by the manufacturer. An ELISA kit with suitable range $(3-300 \mathrm{pg} / \mathrm{mL})$ that had previously performed best overall compared to several other immunoassay kits [150] was chosen. ELISA is based on the principle of competitive binding between the substance of interest in the samples and enzyme-conjugated substance for a constant amount of anti-substance polyclonal antibody attached to the wells. Enzyme-conjugated substance bound to the well decreases as the concentration of the substance in the sample increases. After the wells are washed, a reagent is added resulting in a color development. The intensity of the color is determined by the amount of bound enzyme-conjugated substance remaining in the wells. The color development is stopped with the addition of stop solution, and the absorbance is measured spectrophotometrically. Absorbance in the wells is compared with a standard curve produced in the same analysis using known concentrations of the substance.

Serum samples in Paper IV were analyzed in duplicate using a commercial ELISA kit (Mouse/Rat Estradiol ELISA kit, Calbiotech, Spring Valley, CA, USA). Samples expected to have concentrations above the range of the kit were diluted 1:16 according to recommendation from the kit manufacturer (phosphate-buffered saline with 1\% bovine serum albumin; Sigma-Aldrich Sweden AB, CAS\#9048-46-8, Stockholm, Sweden).

\subsubsection{Uterine weight}

Uterine weight is a frequently used bioassay for estrogenic effects [141, 144, 151, 152] and this outcome was used in Paper I to assess the value of such an approach and investigate the correlation with serum $17 \beta$-estradiol concentrations. Immediately 
after sacrifice, the uteri were removed through an abdominal midline incision and weighed. Since the remaining length of the uterine horns after ovariectomy differed between the animals, the procedure was standardized by weighing only 0.5 centimeter of each uterine horn.

\subsubsection{Assessment of estrous cycle stage}

Rodents, like humans, have a reproductive cycle during which the sex hormone levels fluctuate. However, while the human menstrual cycle is approximately 28 days, the rodent equivalent (the estrous cycle) only lasts 3-6 days. In Paper I, 30 native (non-ovariectomized) controls were included to enable comparison of $17 \beta$-estradiol levels obtained by the different administration methods tested with those of normal cycling mice. To cover the whole range of $17 \beta$-estradiol concentrations occurring over the cycle, the native mice were sacrificed in the three main reproductive stages (proestrus, estrus, and diestrus) as determined by cytological evaluation [80]. With the animal restrained, the tip of a plastic pipette (filled with saline) was placed into the vagina. After flushing three to five times, the final flush was aspired, placed on a glass slide and assessed under light microscope. The proportion of three different cell types (epithelial cells, cornified cells and leukocytes) in the vaginal smear revealed the cycle phase.

\subsubsection{Infarct size measurement}

In Paper IV, infarct sizes were measured $24 \mathrm{~h}$ after middle cerebral artery occlusion with the commonly used 2,3,5-triphenyltetrazolium chloride (TTC) method. TTC was first synthesized in 1894, originally to test viability of seeds and has been used for mammalian tissue since 1958 [153]. The transparent compound is reduced to red colored 1,3,5-triphenylformazan in living tissue by enzymes in viable mitochondria [154]. For brain slices after focal cerebral ischemia, this results in the infarct remaining white while the rest of the brain turns red. It is a cheap and convenient method, fresh slices are used and no microscopic evaluation is required. Under isoflurane anesthesia the rats were decapitated with a rodent guillotine, the brains were dissected out and cooled in ice water for 5 minutes and sliced in $2 \mathrm{~mm}$ slices using a rat brain matrix (RBM-4000, ASI Instrument Inc., USA). Subsequently, the slices were soaked in 2\% 2, 3, 5-triphenyltetrazolium hydrochloride solution (TTC; Sigma-Aldrich Sweden AB, CAS\# 298-96-4, Stockholm, Sweden) at $37^{\circ} \mathrm{C}$ for 15 minutes and scanned (ScanJet 2c, Hewlett-Packard, Palo Alto, CA, USA). Infarcts were measured in a similar way as described by Goldlust et al [155], with an automatic $40 \%$ green spectrum threshold (SigmaScan Pro 5, Systat Software Inc, San Jose, CA, USA). Edema correction was performed according to the following formula:

Corrected infarct volume, as part of one hemisphere $=$ [crude infarct area $x$ [contralateral hemisphere / ipsilateral hemisphere]] / contralateral hemisphere 


\subsubsection{Modified sticky tape test}

In addition to directly evaluate the size of the infarct, different behavioral tests are often used in experimental stroke studies. Such combined outcome evaluation seems logical since the important issue for patients is obviously the function, rather than the appearance of the brain tissue.

In Paper IV, the modified sticky-tape test (MST) was performed similarly to the procedure that Sughrue et al. described [156]. This is a commonly used test for somatosensory dysfunction in rodents. A $30 \mathrm{~mm}$ segment of green autoclave tape was wrapped around the right forepaw (impaired side; contralateral to the ischemic hemisphere), leaving only the fingers protruding slightly from the sleeve. The rat was then placed in a transparent cage $(36 \times 19.5 \times 18.5 \mathrm{~cm})$ and during 30 seconds, time spent attempting to remove the tape sleeve either by biting or scratching with the left paw, was recorded. Two timers were used for this, one to count down the 30 seconds and one that was turned on only while the rat attended to the stimulus, i.e. tried to remove the tape. The intent was for the tape sleeve not to come off, but on the few occasions when the rat pulled so vigorously that it managed to remove it, the time attending to the stimulus was set to the maximum 30 seconds. The test was performed pre-MCAo and 24 hours post-MCAo and the average of two testing sessions per rat on each occasion was used.

\subsubsection{Blinding}

In Paper IV, one experimenter blinded to treatment performed all stroke surgeries and behavioral testing. Another experimenter performed ovariectomies, hormone administrations, blood samplings, sacrifices and infarct size analyses. Infarct size analyses were performed in a randomized and blinded fashion.

\subsubsection{Statistics}

Choosing appropriate statistical methods is pivotal for reliable science. However, this task can be complicated and requires a combination of adequate mathematical training and profound understanding of study design.

In Paper I, 17ß-estradiol concentrations and uterine weights of the experimental groups were compared to non-treated ovariectomized controls by Welch's t-test (2005, Graphpad Software, Inc., CA, USA). All calculations were subsequently Bonferroni adjusted so that the risk of type I errors was $5 \%$ within each administration regimen. The same methods were used to compare animals with and without a washout period prior to hormone administration. Correlation between 17 $\beta$-estradiol concentrations and uterine weights was calculated by Pearson's test (2007; Microsoft Corporation, Redmond, WA, USA). Data were presented as mean \pm SEM throughout the article.

In Paper IV, a power calculation was performed prior to the study in an attempt to estimate adequate group sizes. With an increase in lesion size of $40 \%$ in the high 
dose group, a CV\% of 50 for infarct sizes and sample sizes of 40 , the statistical power would be 0.84 . In the main analyses, i.e. comparisons between the capsule groups regarding infarct size and performance in the modified sticky-tape test, a nonparametric “total outcome" Kruskal-Wallis model with Dunn's post-hoc test was used. Rats that died after MCAo (included mortality) were included in the analysis and were assigned the worst possible outcome. As a complementary analysis, after it had been observed that the relation between dose and outcome seemed linear, Spearman correlation was performed. For 17 $\beta$-estradiol concentrations, three Kruskal-Wallis tests with Dunn's post hoc test were used to compare groups on days 2, 7 and 14. Non-parametric analysis was chosen because a few concentration outliers would have had too large impact in a parametric analysis. Mixed-design (split-plot) ANOVA (analysis of variance) was used to compare body weights over time between groups, with measuring day as within-subject factor and group as between-subject factor. Weights were normalized to each animal's value pre-ovariectomy. P-values $<0.05$ were considered statistically significant.

\subsubsection{Exclusions and protocol violations}

In Paper I, five animals in Gr.P0.18 and one animal in Gr.P0.72 were excluded due to abscess formation around the pellet and all but one were replaced. One animal in Gr.Sil1 and 12 animals in Gr.Sil2 were excluded because the silastic capsule protruded through the skin, and nine of them were replaced. One animal in Gr.Po developed a wound on the back and was subsequently excluded and replaced. This resulted in a total of 11 missing blood samples. In addition, five of the remaining 371 serum samples were excluded as outliers (confirmed by Dixon's test).

In Paper IV, we strived to minimize exclusion of animals by also including postMCAo mortality in the non-parametric statistical analysis (assigned worst possible outcome, see Statistics). However, rats that died before the end of MCAo surgery (excluded mortality, seven animals) were excluded from the study in line with the exclusion criteria stated prior to the study. Further, one of the surviving rats did not contribute with infarct size due to technical problems during scanning of brain slices. Lastly, four samples had $17 \beta$-estradiol levels above the measurement range of the assay despite dilution, the concentrations in these cases were set to the upper limit of the measurement range.

\subsection{Meta-analytical studies (Papers II, III, and V)}

\subsubsection{Procedures of Papers II and V}

Simplified, the standard approach in the majority of the preclinical stroke studies consists of three steps: 1) focal cerebral ischemia is induced in rodents, 2) some kind of treatment is administered and 3) outcome, most often by measuring infarct sizes, is assessed. These basic steps are employed in hundreds of publications each year and in almost all studies a control/placebo/vehicle group is included. These controls groups were considered suitable for inter-study comparisons since they only 
differed regarding methodology, not treatment. Similar methodology was used for data retrieval in Papers II and V.

The basic outline for Papers II and V was pre-defined and consisted of the following steps:

1. Variables to be studied were chosen

2. Data about chosen variables were extracted from relevant articles

3. Variable categories were refined based on extraction results

4. Statistical analyses were performed on variables left after refinement

\subsubsection{Hypotheses}

The hypotheses tested were stated a priori and differed somewhat between Papers II and V. In both analyses, separate analyses were performed for the outcomes infarct size variability and mortality rate.

Hypotheses in Paper II:

1. Rat strain affects (A) infarct size variability and (B) mortality.

2. Type of focal ischemia procedure affects (A) infarct size variability and (B) mortality.

3. In studies using the intraluminal filament method, the type of filament affects (A) infarct size variability and (B) mortality.

Hypotheses in Paper V:

1. Middle cerebral artery occlusion duration affects (A) infarct size variability and (B) mortality.

2. Type of focal cerebral ischemia procedure affects (A) infarct size variability and (B) mortality.

3. Mouse strain affects (A) infarct size variability and (B) mortality.

4. In studies using the intraluminal filament method, the type of occluding filament affects (A) infarct size variability and (B) mortality.

\subsubsection{Article inclusion}

Relevant articles were identified in the Medline database via PubMed using defined search strings:

- (mcao or "middle cerebral artery occlusion" or "MCA occlusion" or "stroke" or "cerebral ischemia" or "brain ischemia") and (rat or rats) in Paper II resulting in more than 19,000 hits.

- (mcao or "middle cerebral artery occlusion" or "MCA occlusion" or "stroke" or "cerebral ischemia" or "brain ischemia") and (mouse or mice) in Paper V, resulting in more than 6,000 hits. 
The articles were consecutively assessed for inclusion, in order of PubMed identifier and assessed for inclusion based on the following criteria:
A. Article written in English
B. Original research article
C. Experiments performed using living animals
D. Animals inflicted one single focal cerebral ischemic lesion
E. Infarct sizes measured and results presented
F. Inclusion of a control group, untreated except for vehicle/placebo treatment
G. Experiment adequately described

In Paper II, 346 articles describing 502 control groups were included while 1084 articles were excluded. In Paper V, a total of 500 control groups from 334 articles were included and 1784 articles were excluded. However, not all control groups could be included in all analyses.

\subsubsection{Data exctraction and processing}

Control group data were extracted from all included articles. If an article described more than one control group, differing in any methodological aspect, these were included separately and analyzed independently. The principle "if it was not described, it was not performed" was adhered to throughout the process. The goal was to gather as much relevant data as possible in order to build a good statistical model, and we strived to include all extractable parameters that presumably could affect the two outcomes mortality and infarct size variability.

To avoid small categories being attributed statistically unsubstantiated explanatory value, categories represented by less than 5 control groups were pooled in an Other category for that specific variable. Other reductions in number of categories were also performed to create meaningful classifications. For example in Paper II, different ways of directly occluding the middle cerebral artery using either a vascular clip or ligation were put together in a Type of focal cerebral artery occlusion procedure category called Direct, mechanical.

\subsubsection{Procedures of Paper III}

Paper III was a sequel to a previous systematic analysis [73] performed in our lab in which the same question was investigated, namely the effect of administration method and estrogen treatment dose on ischemic stroke in rat studies. The statistical shortcomings of the previous systematic analysis, the continuing debate on the matter and the publication of several additional original studies encouraged us to perform this updated and improved study.

In its design, Paper III has some resemblance to Papers II and V described above. However, the outcome studied was estrogens' impact on stroke rather than infarct 
size variability and mortality rate. Nevertheless, the same basic steps applied:

1. Variables to be studied were chosen

2. Data about chosen variables were extracted from relevant articles

3. Variable categories were refined based on extraction results

4. Statistical analyses were performed on variables left after refinement

\subsubsection{Hypotheses}

Three hypotheses were stated a priori: (A) estrogen administration mode, (B) the age of the experimental animals. and (C) the length of hypoestrogenicity affect estrogens' impact on stroke.

\subsubsection{Article inclusion}

To define articles for the meta-analysis, Medline was searched with the search string (stroke OR "cerebral ischemia" or "brain infarction" or "cerebral infarction" or "brain ischemia" or mcao or "middle cerebral artery occlusion") AND (estrogen OR estradiol OR estrogens) and (rat OR rats). The articles retrieved by the search together with the articles included in the previously mentioned systematic analysis, in total 333 papers, were independently assessed for inclusion by two researchers. A specific study was included if all the following criteria were met:
A. Article written in English
B. Original research article
C. The experiment was performed in adolescent, adult or elderly rats
D. The rats were males or ovariectomized and/or reproductively senescent females
E. Each estrogen treatment group had a corresponding control group, and no factor except the estrogen administration per se differed between the groups
F. No other treatments were administered in parallel to the estrogen regimen
G. One single focal cerebral ischemic lesion was induced in the animals
$\mathrm{H}$. The estrogens were administered prior to or at the time of MCAo
I. Infarct sizes were assessed and results presented

Consensus was reached to include 61 studies, of which 45 were included in the previous systematic analysis. Several articles included more than one pair of an estrogen-treated group and a corresponding control group, differing in for example euthanasia time point. All these group pairs were separately included and assessed independently of each other. In the 61 studies, 124 pairs of estrogen-treated groups and control groups were identified.

It was initially the intention to expand the meta-analysis by setting up parallel models for studies in mice. However, the search line (stroke OR "cerebral ischemia" or "brain infarction" or "cerebral infarction" or "brain ischemia" or mcao or "middle cerebral artery occlusion") AND (estrogen OR estradiol OR estrogens) and (mice 
or mouse) only identified 22 articles eligible for inclusion, with too few group pairs to substantiate the planned multiple regression analysis. Further, in only one single group pair, after isoflurane-preconditioning, estrogens were found to increase damage from focal cerebral ischemia. Therefore, it was decided to let rat studies be the sole focus of this article.

\subsubsection{Data extraction and processing}

Method variables were chosen with the aim to encompass all methodological aspects that theoretically could influence estrogens' effects on ischemia. When extracting the method data, the principle "If it was not described, it was not performed" was adhered to. When possible, categories represented by less than 5 group pairs were in the analysis clumped up in an Others category. Further, some other reductions in number of categories were performed to create meaningful classifications.

The three variables Slow-release pellets: estrogen dose/pellet, Injections: daily estrogen dose and Silastic capsules: estrogen dose/silastic capsule, were not included in the main multiple regression model, since each of these variables was only relevant for a limited number of group pairs. These categories were instead used in subsequent simple linear regression models.

The outcome variable Infarct size ratio between estrogen treated and control rats ("EC-ratio") was calculated by simply dividing the mean infarct volume in the estrogen treated group by the mean infarct volume in the control group, and then multiplying by 100 to yield a percentage. Hence, a percentage above $100 \%$ means that the estrogen group on average suffered from larger (nominally; whether significant or not) infarctions than the control group, while numbers below $100 \%$ indicates the opposite. For example, a group pair in which estrogen treatment halved the infarct size would obtain an EC-ratio of 50\%.

\subsubsection{Statistics}

In multiple linear regression (Papers II, III, and V) several decisions regarding method for building the model have to be made (e.g. limit for excluding variables and order of variable insertion in the model), and these will affect the results and have to be taken into account when drawing conclusions. Multiple linear regression is an extension of classic simple linear regression with one predictor and one outcome variable; still only one outcome variable is studied, but now several predictors are incorporated into the model.

Papers II and V were very similar from a statistical point of view and are therefore described together. However, minor differences are pointed out when relevant.

To perform proper a priori power calculations for such large multiple regression models is a very complex task. Instead, for Paper II, a saturation principle was adopted 
to determine a sufficient number of control groups to be included. After information from 300 control groups had been extracted, an interim analysis was performed, and then re-performed every 40-50 new control groups included. When the results had stabilized (no changes in overall trends, and only minor changes in p-values), no more articles were included. 502 control groups from 346 articles were finally included in the study while 1084 articles were excluded. The number of control groups to be included in Paper V was then based on the previous similar meta-analyses (Paper II). In addition, interim saturation analyses were performed after 400 and 450 included control groups to check when the results had stabilized, i.e. no changes in overall trends occurred. In total, 500 control groups from 334 articles were included and 1784 articles were excluded.

Since large multiple regression models may suggest a wide range of unexpected associations between variables, a limited set of predefined hypotheses were established for Papers II and V to lower the risk of finding falsely significant results due to multiple comparisons (type I errors). Findings not related to these were interpreted with caution and considered merely hypothesis-generating. Due to the risk of type II errors, corrections for multiple comparisons were not performed.

All categories were dummy-converted before analysis. For binomial variables, lack of a specific methodological factor was considered the reference category, whereas the most common category was chosen as baseline for variables with more than two categories. The data were analyzed using weighted multiple linear regression in two steps. First, a backward exclusion procedure identified factors that contributed significantly to the model and removed the rest. Subsequently, an enter model was performed, in which significant factors identified were manually complemented by lacking dummy variables that were excluded in the previous step. Weighting of cases was performed according to the number of animals in each control group; hence, a study including 10 animals in the control group was given less impact than a study including 20 animals. Four regression models were set up in Paper II (one for hypotheses $1 \mathrm{~A}$ and $2 \mathrm{~A}$, one for hypotheses $1 \mathrm{~B}$ and $2 \mathrm{~B}$, one for hypothesis $3 \mathrm{~A}$ and one for hypothesis $3 \mathrm{~B}$ ) and four in Paper $\mathrm{V}$ (one for hypotheses $1 \mathrm{~A}, 2 \mathrm{~A}$, and $3 \mathrm{~A}$; one for hypotheses $1 \mathrm{~B}, 2 \mathrm{~B}$, and $3 \mathrm{~B}$; one for hypothesis $4 \mathrm{~A}$ and one for hypothesis $4 \mathrm{~B}$ ). These tested the combined effects of all factors on the two separate outcome measures, Infarct size coefficient of variation or Mortality, and when investigating one of the specific hypotheses, the model controlled for the other predictor variables. The models passed residual checks and multicollinearity tests. All statistical calculations were performed in SPSS (Version 23, IBM Corporation, Armonk, NY, USA). P-values $<0.05$ were considered significant. Regarding results from the meta-analysis, 95\% confidence interval were provided, otherwise data were presented as mean \pm standard deviation.

The multiple linear regression approach of Paper III had many similarities with that of Papers II and V. Data regarding methodological factors, extracted from previously 
published articles, were the predictor variables. However, the outcome variable was estrogens' impact on stroke, or more specifically Infarct size ratio between estrogen treated and control rats ("EC-ratio", described above). Further, Number of rats in estrogen treated and control groups attributed each group pair (estrogen-treated group and control group) a weight in the analysis, and all other extracted variables (except the excluded ones, and the administration mode-specific dose variables) were considered independent factors. All category variables were dummy-converted before analysis and the main multiple regression analysis consisted of two steps, a backward exclusion (p-value set to 0.10 for exclusion) and an enter procedure. The enter procedure included the significantly affecting variables from the backward model, together with lacking dummy variables so that all categories within a certain variable were included. Also, group pairs in which slow-release pellets, injections and silastic capsules had been used, respectively, were separately analyzed for association between dosage and EC-ratio. Even if three further large multiple models, as the main model described above, would theoretically have been preferable to control for confounders, the number of groups pairs pertaining to any of the three administration mode categories was too low (in the range of 30-50) to sustain an adequate statistical power. Instead, the relation between dosage and EC-ratio was analyzed with simple linear regression models.

All statistical calculations were performed in SPSS (Version 20, IBM Corporation, Armonk, NY, USA). P-values $<0.05$ were considered statistically significant.

\subsubsection{Exclusions and protocol violations}

In Papers II, III, and V, variables intended to be included but were reported in too few articles had to be omitted from the analyses. In Paper II, in an effort to fill the gaps, the authors of articles lacking certain information were contacted via e-mail with a gentle request to provide this information. Further, in the silastic capsule subanalysis of Paper III, the three group pairs that received silastic capsules containing crystallized $17 \beta$-estradiol were excluded due to difficulty in translating to dissolved concentrations. 


\section{Results and Discussion}

\subsection{Differences between administration methods (Paper I)}

The unexpected findings of the 2005 study by Theodorsson and Theodorsson [1], that $17 \beta$-estradiol increased ischemic lesions in that rat model of focal cerebral ischemia, warranted scrutiny of the methods used in that study in general and the hormone administration method in particular. A review of the literature revealed that few studies had thoroughly characterized the performance of different ways of administering $17 \beta$-estradiol to rodents, and it was decided to attempt to fill this knowledge gap. Thus, in three subsequent experiments [108-110] the commonly used subcutaneous administration methods were assessed and it was found that the popular slow-release pellets (used in the previous study with increased damage) were very unreliable in terms of hormone concentrations produced in plasma. Although these studies provided valuable information for our group as well as others, all three exclusively focused on rats and therefore the results were not directly applicable for the growing community of researchers working with mice. Therefore, it seemed to be a natural next step to perform an experiment to evaluate $17 \beta$-estradiol administration methods also in mice.

The experiment, resulting in Paper I, compared serum concentrations achieved by the previously well-used used subcutaneous long-term $17 \beta$-estradiol administration methods, slow-release pellets from the company IRA and home-made silastic capsules. We also characterized, both in short- and long-term perspective, a novel peroral method with $17 \beta$-estradiol administered in the hazelnut/chocolate spread Nutella ${ }^{\circledR}$. Further, the mice receiving silastic capsules were divided into two groups, with or without a washout period after ovariectomy, to enable comparison of these approaches. Similar to what was found in the rat studies, the silastic capsules produced concentrations that were within or slightly above the physiological range, although declining slowly over time (Figure 4C). Also the peroral method performed well with concentrations predominantly within the physiological range (Figure 4D). In contrast, the slowrelease pellets proved to be an unreliable and unpredictable administration regimen with initial supraphysiological concentrations decreasing drastically over time in the low-pellet group (Figure 4A), and extremely supraphysiological concentrations with great variability in the high-pellet treatment group (Figure 4B).

The slow-release pellets are popular, and this is probably explained by their convenience. Although expensive, they are easy to order from the company IRA. Some previous studies have attempted to evaluate the pellets using bioassays, e.g. uterine weight and vaginal smears [144], or by measuring the $17 \beta$-estradiol concentrations on one single occasion [157]. However, Paper I was the first thorough assessment with $17 \beta$-estradiol concentration measured in samples obtained from mice on multiple occasions during the entire evaluation experiment. This enabled a depiction of the temporal profile of the pellets. 


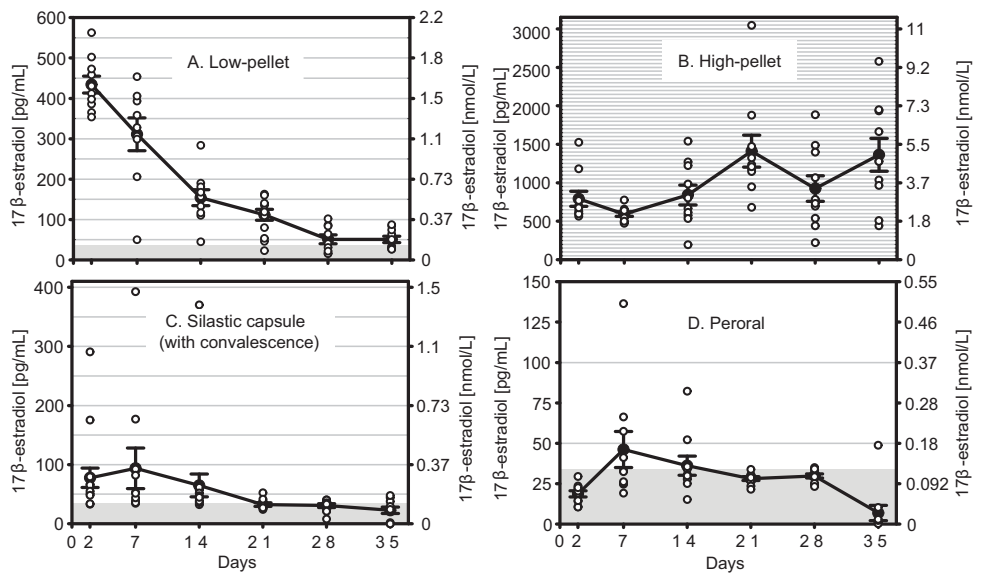

Figure 4. Serum 17b-estradiol concentrations in the treatment groups. (A) 60-day release $0.18 \mathrm{mg}$ pellet (low-pellet group); (B) 90-day release $0.72 \mathrm{mg}$ pellet (highpellet group); (C) silastic capsules after a washout period of 14-21 days; (D) peroral administration in Nutella $^{\circledR}$ ( $n=20$ in each group). The group values are presented as mean \pm SEM and the white circles represent individual sample concentrations. Please note the difference in scale on the Y-axis between the graphs, and that the concentration difference between the grey horizontal lines is $50 \mathrm{pg} / \mathrm{mL}$ in all figures. The grey fields represent the physiological range from the intact control group.

The slow decline of the curve for the silastic capsules most likely reflects a progressive loss of $17 \beta$-estradiol from the oil within the capsules. Nevertheless, the concentration was within the physiological range at the end of the study. Previous studies evaluating the silastic capsules for $17 \beta$-estradiol administration to mice are few. Cohen and Milligan measured the effects of silastic implants (albeit composed in a different manner) on uterine weight and vaginal smears and found that a physiological response could be achieved [144]. However, they did not measure hormone concentrations. An advantage of the silastic capsules is that they are very cheap compared to the pellets. However, since they are not commercially available, researchers themselves have to assemble the capsules which takes some time and makes them less standardized.

Since estrogens are usually administered perorally in the clinic, an animal model where the hormone is delivered by this route appears attractive for pharmacokinetic reasons. Other advantages of the peroral method are that it is cheap, non-invasive, and does not require anesthesia. On the other hand, daily administration is required and the animals will not only be exposed to $17 \beta$-estradiol but also extra energy and different substances in Nutella ${ }^{\circledR}$. Even though previous attempts have been made at peroral administration, e.g. by oral gavage [158, 159] and drinking water [141, 151], these methods have, apart from several other shortcomings, not been investigated by consecutive serum $17 \beta$-estradiol measurements. Nutella as a medium for peroral 
administration to mice has previously been used to administer buprenorphine [146], but its use with 17ß-estradiol has not been reported except in the corresponding rat study from our lab [110].

The findings of Paper I are important both for researchers' choice of $17 \beta$-estradiol administration method in future studies, and for the interpretation of past studies. For example, if the slow-release pellets were chosen based on the manufacturers claim that they provide even release during the designated release time [160] and hormone concentrations were not measured, it might have been that the actual levels differed substantially from what was intended. The pellets might be useful if very high pharmacological levels are desirable, but their unpredictability (as shown in the present study as well as our previous studies on rats [108-110]) makes them problematic. Instead, it can be recommended to use the silastic capsules that despite their simple appearance were relatively constant in their hormone release with levels slightly above or within the physiological range. Alternatively, if the goal is to closely mimic the clinical situation of peroral administration of estrogens, the Nutella ${ }^{\circledR}$ method would be suitable. Regarding the use of a washout period, no significant difference was found between the two silastic capsule groups, and thus a washout period does not seem to influence the serum concentrations. However, the use of a convalescence period is recommended to allow the stitches from the ovariectomy to heal completely as to avoid protrusion of the capsule through the skin.

\subsection{Estrogens and stroke - aspects of administration methods and dose (Papers III and IV)}

As described above, the pellets used in the previous stroke study from our lab resulting in increased stroke damage from estrogens [1], were in subsequent administration studies shown to produce very high serum concentrations of $17 \beta$-estradiol [108-110]. This led to the suggestion that perhaps the mode of administration, and hence delivered dose, could explain why some estrogen-stroke studies had demonstrated increased damage while the majority pointed in the opposite direction. Such a bidirectional dose-response curve would be an example of estrogen hormesis, which has been demonstrated before regarding e.g. growth of cultured tumor cells (1.4.3.). The idea was supported by a systematic review and meta-analysis of all studies on the effects of estrogens of cerebral ischemia in rats by Ström et al. in 2009, reporting that the slowrelease pellets had been used in all studies showing detrimental effects. Although such a hypothesis may seem unattractive because it is not readily extrapolated to the human studies, where the range of tested dosages is extremely narrow, it seemed an unlikely coincidence. However, in the 2009 study, separate analyses handled one variable at a time, and thus confounders were not controlled for. The statistical shortcomings of the previous analysis, the continuing debate on the matter and the publication of several additional original studies encouraged us to in 2014 perform an updated and improved meta-analysis. This resulted in Paper III.

In the new meta-analysis (Paper III), all methodological differences that reasonably 
could affect the impact of estrogens on experimental ischemic stroke were controlled for in a large multiple regression model with the main outcome EC-ratio. The main model revealed a clear impact of estrogen administration mode on the effects of estrogens in ischemic stroke (Figure 5). Slow-release pellets significantly differed from the injection and silastic capsule treatments, showing that slow-release pellets are more prone to render estrogens damaging. Of note, the slow-release pellet confidence interval extended over the 100\% EC-ratio line, underscoring the potential for harm as well as benefit (Figure 5). Further, administration mode-specific simple regression models between dose and EC-ratio were run (Figure 6). While no statistically significant relation was seen for injection or silastic capsule, higher slow-release pellet dose was clearly related to increased ischemic damage. Thus, the updated meta-analysis was in line with earlier findings, even with additional published data included and an improved study design. Although mentioned as possible explanations to diverging results in estrogen-stroke studies in animals as well as humans (1.4.2), no impact of the use of elderly animals or a long wash-out period (hypoestrogenicity period prior to estrogen treatment) was seen.

\section{Confounder-controlled infarct size ratio between estrogen treated and control rats [\%]}

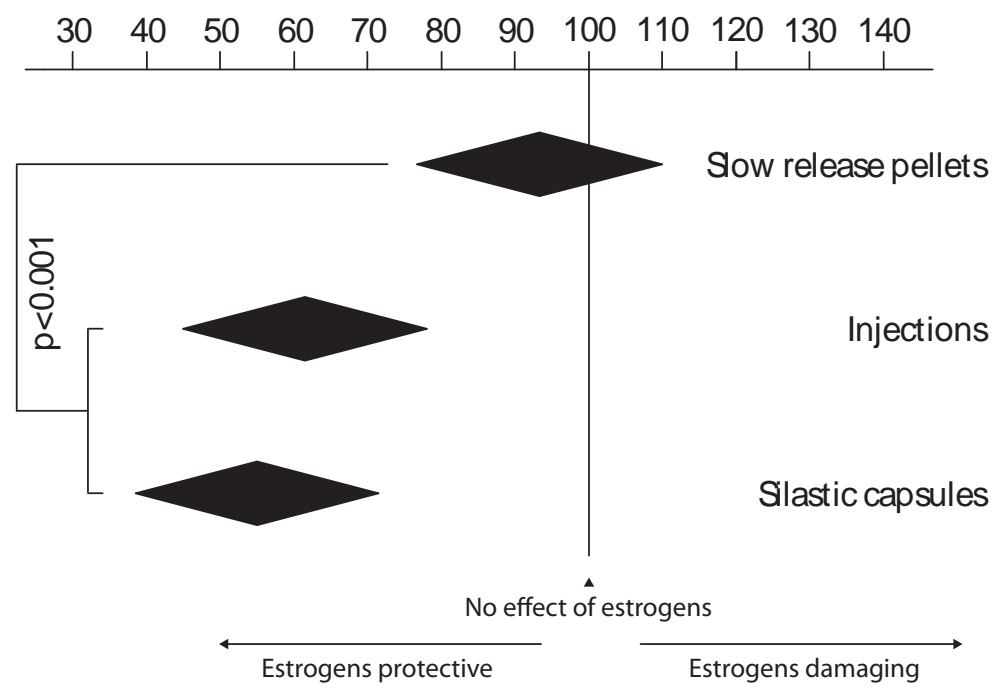

Figure 5. Impact of estrogen administration mode on the effects of estrogens in ischemic stroke. After controlling for confounding factors, it remained clear that slowrelease pellets rendered significantly higher EC-ratios than the injection and silastic capsule regimens did $(p<0.001)$. The black diamonds mark the mean EC-ratio with 95\% confidence interval for each of the three administration modes. Of note, the slow-release pellet diamond reaches over the $100 \%$ EC-ratio line, demonstrating the pellets' potential for harm as well as protection. EC-ratio = infarct size in estrogen treated group divided by infarct size in control group. 

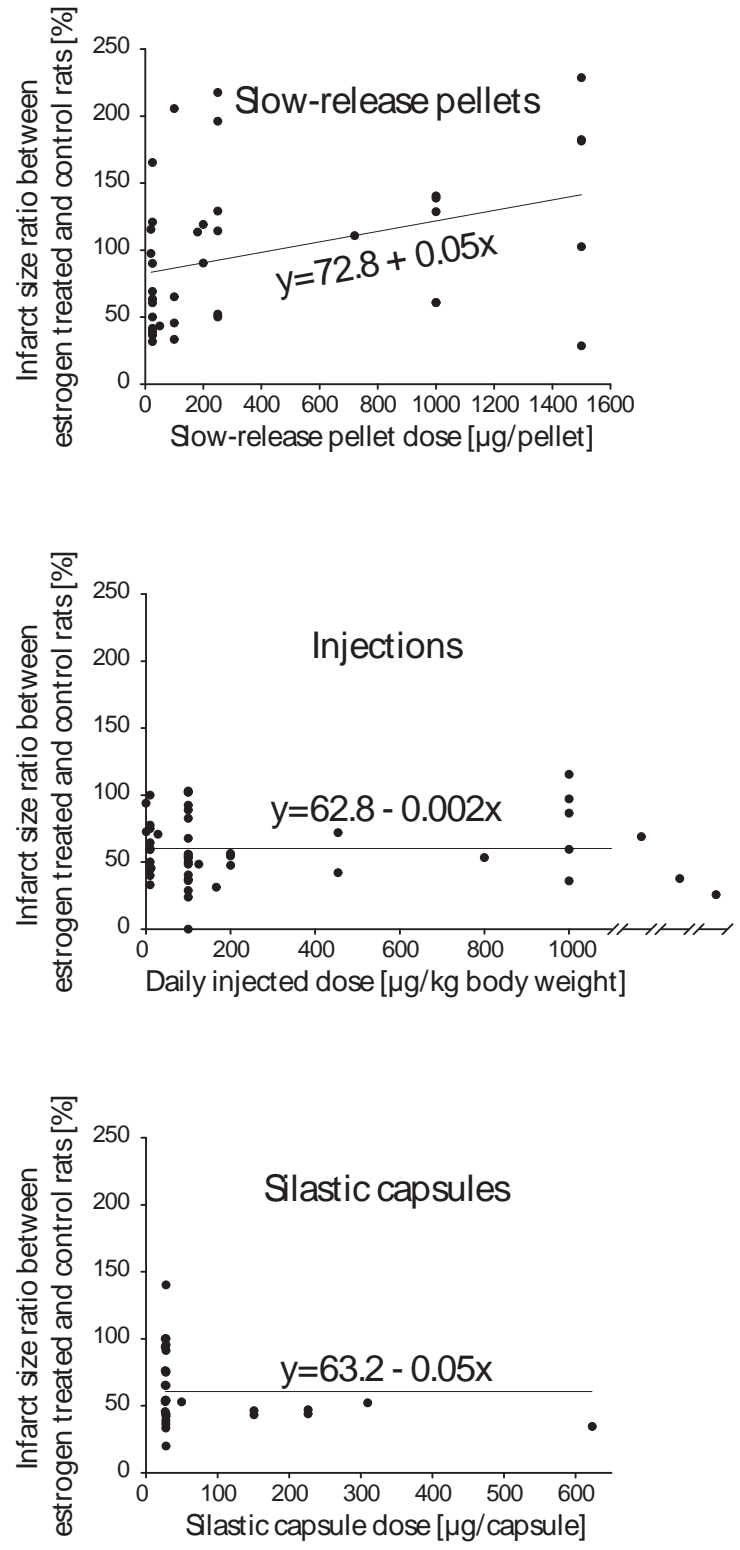

Figure 6. Administration mode-specific simple regression models between dose and EC-ratio. By three simple linear regression analyses, it was found that higher pellet doses significantly increased EC-ratio $(y=72.8+0.05 x ; p=0.001)$, while there was an opposite trend (not significant) among injection and silastic capsule regimens. The numbers of group pairs included in the slow-release pellet, injection and silastic capsule simple regression models were 39, 50 and 31, respectively. Note that the injection graph has been compressed in the upper dose range to accommodate three group pairs being administered very high doses. 
Thus, the meta-analyses supported the hypothesis of dose-related neuroprotection vs neurodamage in response to $17 \beta$-estradiol administration. In addition, the 2005 experimental estrogen-stroke study had been repeated with $17 \beta$-estradiol administered in silastic capsules instead of pellets and interestingly, now a protective effect was found [31]. However, it remained to be proven that estrogens both exert neuroprotection and promote detrimental effects depending merely on dose and independent of the administration route. Therefore, a new experiment was designed with the objective to test whether a high-dose silastic capsule (designed to give rise to similar concentrations of estrogens as the neurotoxic pellets) would increase ischemic damage, whereas a low-dose capsule would decrease the damage. This resulted in Paper IV.

Surprisingly and in contrast to the hypothesis, in the following study (Paper IV) a significant negative correlation was found between $17 \beta$-estradiol dose group and infarct size meaning that the higher the dose, the smaller the infarcts (Figure 7). Thus, the hypothesis that the high-dose group would have the most severe damage while the low-dose group would have the mildest was not confirmed.

With the aim of investigating the same hypothesis, a study by Ma et al. was published in 2013 [161]. True hormesis, with bidirectional effects in different dose ranges compared to baseline, could be demonstrated in the in vitro oxygen-glucose

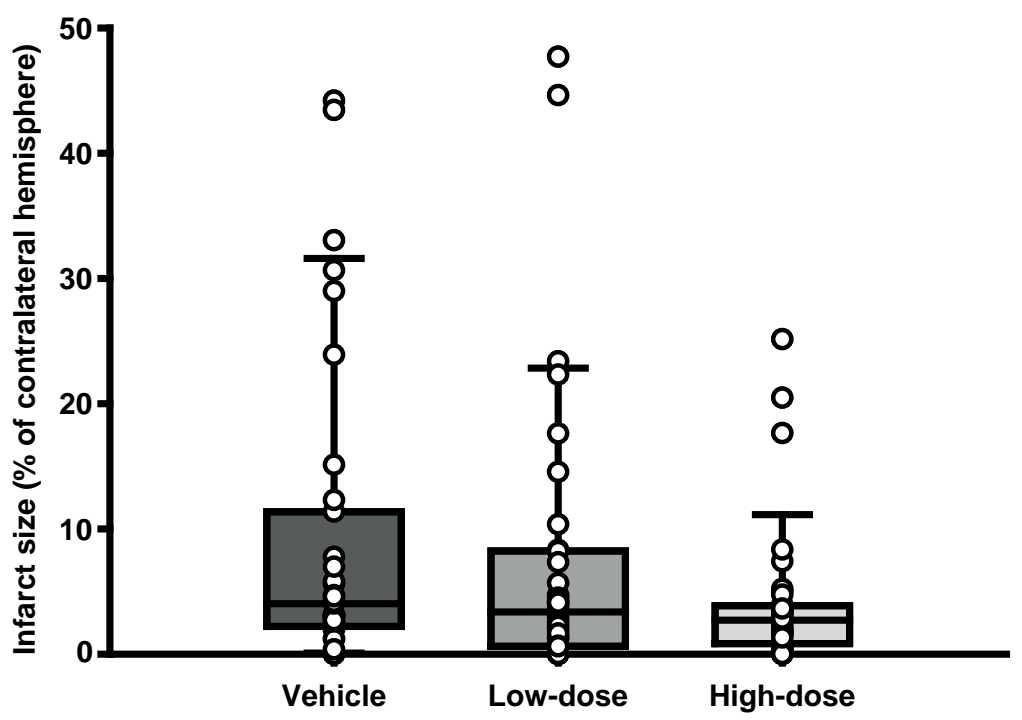

Figure 7. Infarct sizes of groups subjected to middle cerebral artery occlusion (MCAo). No significant differences were found between the groups $(p=0.054)$. However, a trend towards more favorable infarct outcome with higher $17 \beta$-estradiol dose was noted, which was confirmed by Spearman correlation analysis $(\mathrm{p}=0.018)$. Whiskers indicate the $90^{\text {th }}$ and $10^{\text {th }}$ percentiles. 
deprivation experiments. However, rather than augmented damage, the in vivo experiment only found attenuated protection.

In the light of earlier findings from our lab and others, the results of Paper IV were indeed unexpected. One explanation could be that our high dose capsules did not manage to keep the serum estrogen concentrations high enough during the entire study, since they actually resulted in about half of the pellet induced serum concentrations on day at the time of MCAo. It could also be that a high dose is but one of several methodological parameters required for the detrimental effect of estrogens to occur, and that those other elements were lacking. Otherwise, the results presented in Paper IV suggest that in the studies where estrogen treatment have caused enlarged infarcts, some other factor than high delivered dose was the culprit. However, the fact that all studies reporting detrimental effects of estrogens have used the slow-release pellets remains hard to explain. It is possible that some pellet matrix component affects the ischemic stroke, but such a claim is merely speculative and perhaps far-fetched given that there are also examples of pellet studies demonstrating neuroprotection [162, 163]. In conclusion, if high estrogen doses/plasma concentrations per se cause increased stroke damage, such a phenomenon is not very robust, and seems to depend on very tight dose ranges and/or other experimental circumstances.

\subsubsection{The clinical situation}

Although conflicting results have been observed in animal as well as human studies, the same explanation might not be applicable for both situations. A discussion regarding the importance of dose and administration route on the effect of HRT on stroke is indeed relevant also for humans, but the dose range is much narrower and the routes of administration are not the same. For example, it has been shown that oral estrogen therapy increase the risk of stroke while low-dose transdermal $17 \beta$-estradiol does not [164]. Perhaps the most apparent problem when comparing animal and human studies is the difference in outcome measure. Human studies focus on stroke incidence, whereas most animal studies are designed to assess stroke severity. However, theoretically it can be argued that the two phenomena might not be completely unrelated. For example, in the Heart and Estrogen-progestin Replacement Study (HERS), registered cerebrovascular events were graded from mild (TIAtransient ischemic attack) via nonfatal to fatal strokes. It was found that that the trend of increased incidence of fatal strokes $(1.61 ; 0.73-3.55)$ was more substantial than the increase of any stroke (1.23; 0.89-1.70) or overall cerebrovascular events (TIA+any stroke; $1.09 ; 0.84-1.43$ ). Thus, an increase in severity could be interpreted as a change of incidence in different categories on the spectrum. The association of severity and incidence can also be illustrated in the perspective of animal studies. In a study from 2003, subcortical infarcts were completely prevented in rats treated with $17 \beta$-estradiol prior to the induction of mild focal cerebral ischemia [165]. Thus, the severity spectrum was changed by preventive treatment and mild strokes turned into no events, at least in terms of histologically measurable infarcts. Stroke incidence studies have been performed in stroke-prone spontaneously hypertensive rats [166], 
but to the best of our knowledge not regarding the effect of estrogen treatment. In hormone replacement treated monkeys, development of atherosclerosis has been studied but not impact on number of stroke events [167]. Animal studies often focus on one single aspect of $17 \beta$-estradiol treatment even though the picture is much more complex in the clinic. Since estrogens have such a wide array of actions, not just the effects on stroke have to be considered when prescribing treatment for vasomotor symptoms, but also e.g. on coronary arteries, uterus and breast.

Mentioned above is the discrepancy regarding route of administration between animal and human studies. Practically all animal studies used parenteral administration whereas the hormones were ingested orally in the majority of the clinical studies. Because of the first passage metabolism, an enteral regimen will give rise to a different pattern of active estrogen metabolites and the temporal serum concentration profile will differ from that obtained with the parenteral methods. In addition, expression of numerous hepatic substances whose synthesis is sensitive to estrogens will be increased. Subcutaneous alternatives with administration via pellets exist for humans as well [168], but are not very commonly used. The inclusion of a peroral Nutella ${ }^{\circledR}$ group in Paper I was an attempt to address this issue and offer a possibility to bridge the gap between preclinical and clinical studies.

\subsection{Method parameters' impact on mortality and variability in rodent stroke experiments (Papers II and V)}

Low statistical power as a result of high outcome variability and mortality in combination with small group sizes has been suggested to be an important factor contributing to the translational failures in stroke research, as described in the Background (1.3.). There are examples of studies that investigated one or a few parameters in order to optimize the ischemia model, but comparing all possible combinations experimentally would be a tedious endeavor and has therefore not been done. As an alternative approach, we extracted data from a total of 680 previously published rodent stroke articles and meta-analyses were performed to investigate how methodological choices affect outcome variability and mortality. This novel meta-analytical approach to methods development resulted in Paper II (focusing on rats) and Paper V (focusing on mice).

The most important findings in Paper II were that the Wistar strain and the intraluminal filament procedure using a silicone coated filament resulted in the smallest infarct size variability (Figure 8). The direct and endothelin methods rendered the lowest mortality rates, while the emboli method increased mortality when compared to the intraluminal filament method (Figure 8). The mouse meta-analysis (Paper V) showed that the use of Swiss and C57BL6 mice as well as permanent occlusion of the middle cerebral artery rendered the lowest infarct size variability while emboli/clot methods increased it (Figure 9). Of the methodological factors investigated, only Swiss mice had a significant impact on mortality rate by increasing it compared to the reference strain (Figure 10). Effect sizes were generally large in the analyses, with many 
parameters changing the outcomes more than $10 \%$ in absolute terms. In addition to the findings pertaining to the hypotheses, several other interesting observations were made. However, since these studies were designed as a hypothesis-driven meta-analyses, results not related to the factor-outcome relations stated a priori were interpreted with caution and considered merely hypothesis-generating. In addition to the main results of Papers II and V, the gathering of data from 680 rodent stroke articles also enabled us to depict the frequencies of different methodological alternatives, an overview presented separately for rats and mice in Figure 11 and Figure 12.

Both Papers II and V hypothesized that strain, type of focal cerebral ischemia procedure, and type of filament (in studies using the intraluminal filament method) would affect mortality and variability. In addition, the mouse study also highlighted a possible effect of occlusion duration. When comparing the two, some similarities as well as differences were noted. Emboli methods were found to render larger coefficient of variation of the infarct size than filament, direct and photothrombosis methods in both studies. Further, permanent ischemia had the lowest variability of the different occlusion durations in Papers II as well as V, although not included among the main hypotheses in the former. In contrast, e.g. regarding types of coating in the filament subanalysis, they do not harmonize; no significant differences were found for mice whereas silicone decreased variability for rats.

The main problem caused by large infarct size variability is the resulting lack of statistical power if the sample sizes are not adjusted accordingly. This has been discussed in several reviews [51, 169, 170]. Statistical power $(1-\beta)$ is often discussed in relation to negative findings, e.g. to evaluate if a study was adequately designed to detect a treatment effect of a substance and hence if the negative results are to trust or not. However, statistical power is of importance also for studies with positive findings (i.e. when a treatment effect is found) [51]. When interpreting significance testing, prior probability has to be taken into account, as pointed out by Sterne and Davey Smith [171] in an educational example: Approximately 10\% of hypotheses in biomedicine are estimated to be true and the statistical power is often around $50 \%$. Under these circumstances, out of 1000 hypotheses tested, 100 are true but only 50 will be detected with a power of 50\%. Further, when the remaining 900 false hypotheses are tested at a 0.05 significance level, 45 will in fact falsely be considered true (5\% of 900). The result is that only 53\% (50/95) of the 95 studies with significant results will be true. Another problem attached to low statistical power is the publication bias phenomenon since negative findings are generally less likely to be published, which can distort interpretation of meta-analyses [58].The issue of mortality is somewhat related to outcome variability and power calculations in that higher mortality require larger group sizes to attain sufficient power. However, there is also another side to the problem. It is difficult to incorporate mortality in the standard parametric methods, perhaps explaining why this information often is not even mentioned. The risk when omitting mortality rate data can be illustrated by the possible scenario of a toxic substance that seems to decrease infarct sizes compared to a placebo group, only 

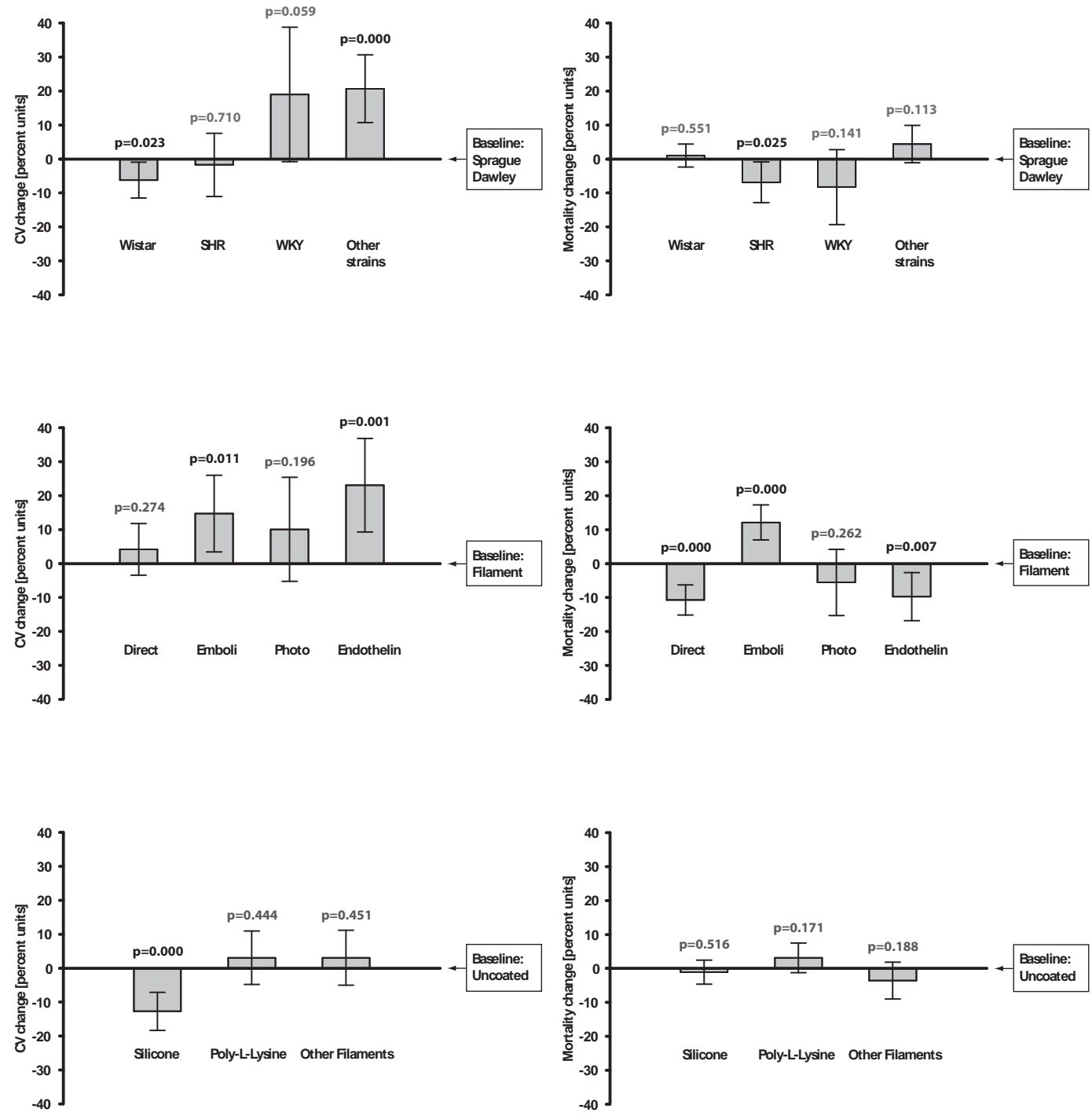

Figure 8. Method parameters' impact on variability and mortality in rat stroke experiments. Bars represent change in infarct size coefficient of variation, measured in absolute percent units. Significances are seen for all hypotheses except the effect of filament type on mortality in studies using the intraluminal filament method. The error bars represent 0.95 confidence intervals. Significant p-values are black, non-significant p-values are grey. For strain, $N=469$ and 351; for occlusion methods, $N=469$ and 351; for filament type, $\mathrm{N}=383$ and 265. $\mathrm{CV}=$ coefficient of variation [calculated as standard deviation/mean]; SHR = spontaneously hypertensive rats; WKY= Wistar Kyoto rats. 

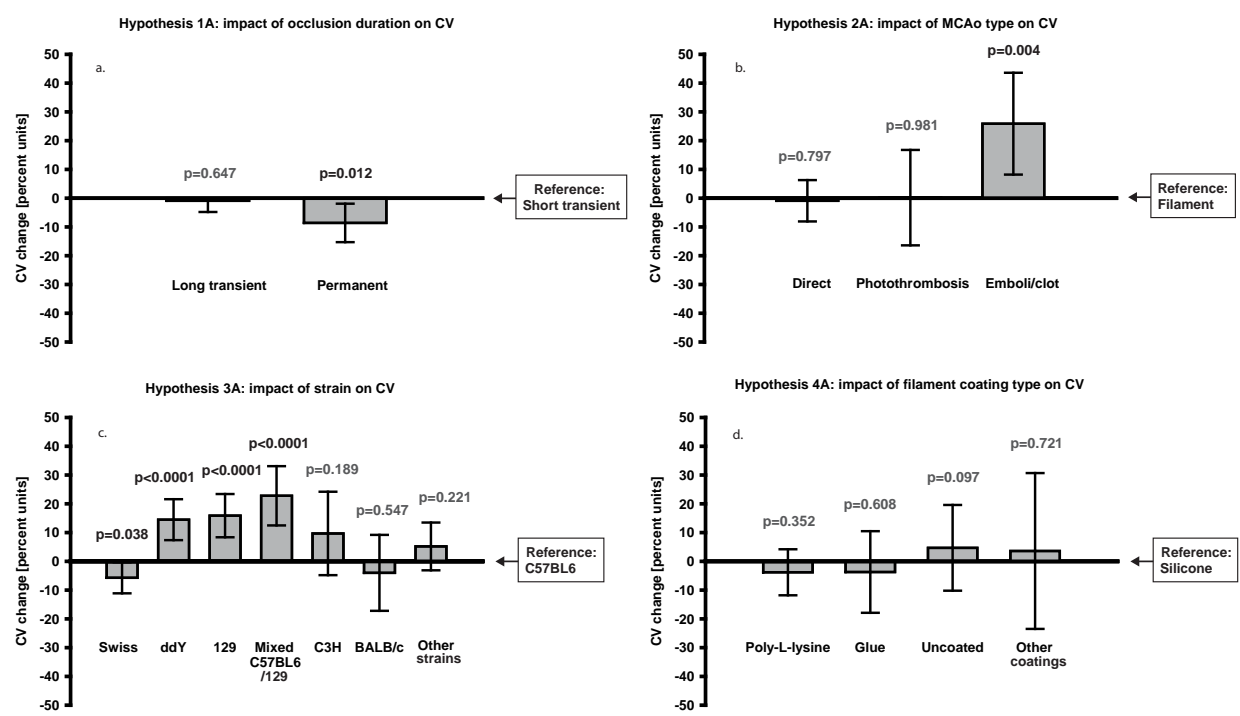

Figure 9. Method parameters' impact on infarct size variability in mouse stroke experiments. Bars represent change in infarct size coefficient of variation, measured in absolute percent units. Significant p-values are black, non-significant p-values are grey. $\mathrm{N}=500$ for $\mathrm{a}$, b and c; $\mathrm{N}=430$ for $\mathrm{d}$. Error bars represent 0.95 confidence intervals. $\mathrm{CV}=$ Coefficient of variation [calculated as standard deviation/mean]; MCAo=Middle cerebral artery occlusion.

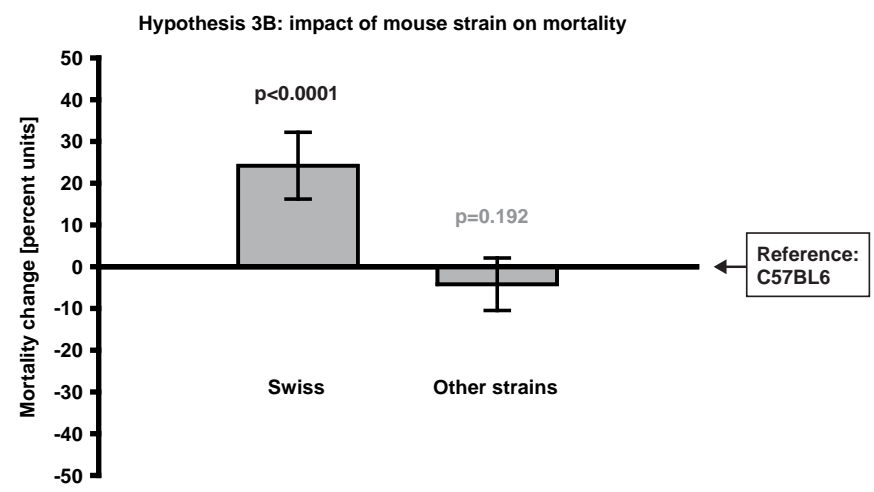

Figure 10. Method parameters' impact on mortality rate. Swiss strain was found to significantly increase mortality rate compared to the reference C57BL6. The variables occlusion duration, type of middle cerebral artery occlusion procedure, and occluding filament type were removed in the backward exclusion step of the regression model due to small explanatory value and therefore results of hypotheses $1 \mathrm{~B}, 2 \mathrm{~B}$, and $4 \mathrm{~B}$ could not be presented. Bars represent change in mortality rate, measured in absolute percent units. Significant p-values are black, non-significant p-values are grey. $\mathrm{N}=80$. Error bars represent 0.95 confidence intervals. 
because all mice with large infarcts in the treatment group died.

Although low statistical power due to high outcome variability and mortality theoretically can be overcome by increasing the group sizes sufficiently, such a solution has several problematic implications. Ethically, it could be considered problematic to drastically increase the number of animals in all experimental stroke studies. Moreover, working with large number of animals requires a lot of time, space and money. Therefore, as a complement it would be attractive in some situations to optimize the animal model by minimizing unnecessary outcome variability and mortality, or at least be able to power studies more exactly by predicting variability and mortality given a certain experimental setup.

\subsection{Strengths and weaknesses of the thesis}

Astrength of this thesis, and the studies that were performed prior to and in parallel with it, is that we put a lot of effort into investigating the methods and in order to improve the designs. This has been helpful for us and hopefully also to other researchers working with similar techniques. We have also strived to be very transparent and clear in our reporting and statistics. For example, to account for mortality in Paper IV, instead of excluding rats that died, a non-parametric "total outcome" model with was used for comparisons between groups. Rats that died after MCAo were included in the analysis and were assigned the worst possible outcome. For the experimental stroke study (Paper IV), six of the eight STAIR criteria (recommendations on methodological quality from the Stroke Therapy Academic Industry Roundtable) were fulfilled. Those were randomization, monitoring of physiological parameters, assessment of dose-response relationship, masked outcome measurement, assessment of outcome days 1-3 and combined measurement of lesion volume and functional outcome. Assessment of optimal time window and assessment of outcome at days 7-30 were not fulfilled. The main strength of the meta-analyses (Papers II, III and V) is the large number of articles included, and that the effects of many different method parameters could be investigated together in one single statistical model. Further, by using previously published data, new questions could be answered without having to use more animals.

However, the thesis also has several weaknesses. Papers II, III, and V have limitations that are inherent to the meta-analytical design as well as those specific for these studies. Meta-analyses always run the risk of being distorted by publication bias. Stroke studies with large coefficients of variation should be more likely to give negative results and thus more likely remain unpublished. In the case of Paper III, it might be that more studies showing a detrimental effect of estrogen exist, but they ended up in a drawer since they contradicted the majority of the previously published material. For all three meta-analyses, in many cases more than one group were used from each article and treated independently in the subsequent analysis. This is not strictly statistically appropriate but creating categories for all unique studies would have made the statistical analyses impossible. Even if this approach controls for many 


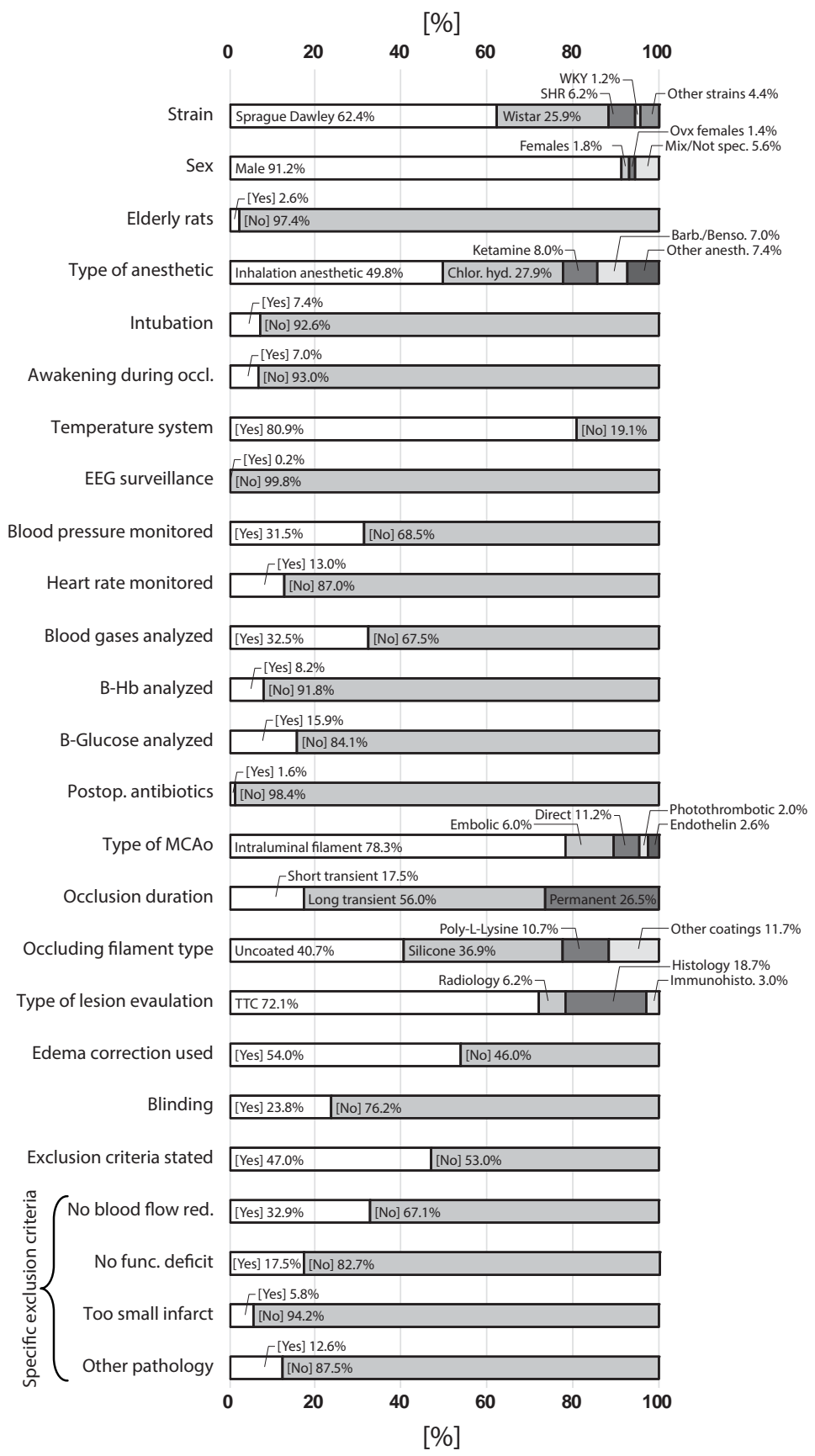

Figure 11. Frequencies of registered categories in the 502 included rat control groups. Many of the variable names are abbreviated in the figure; for extended description, see Paper II. "Histology" in the bar "Type of lesion evaluation” refers to acidic/basic stain or silver stain histology. EEG= electroencephalography, B= Blood, $\mathrm{Hb}=$ Hemoglobin. 


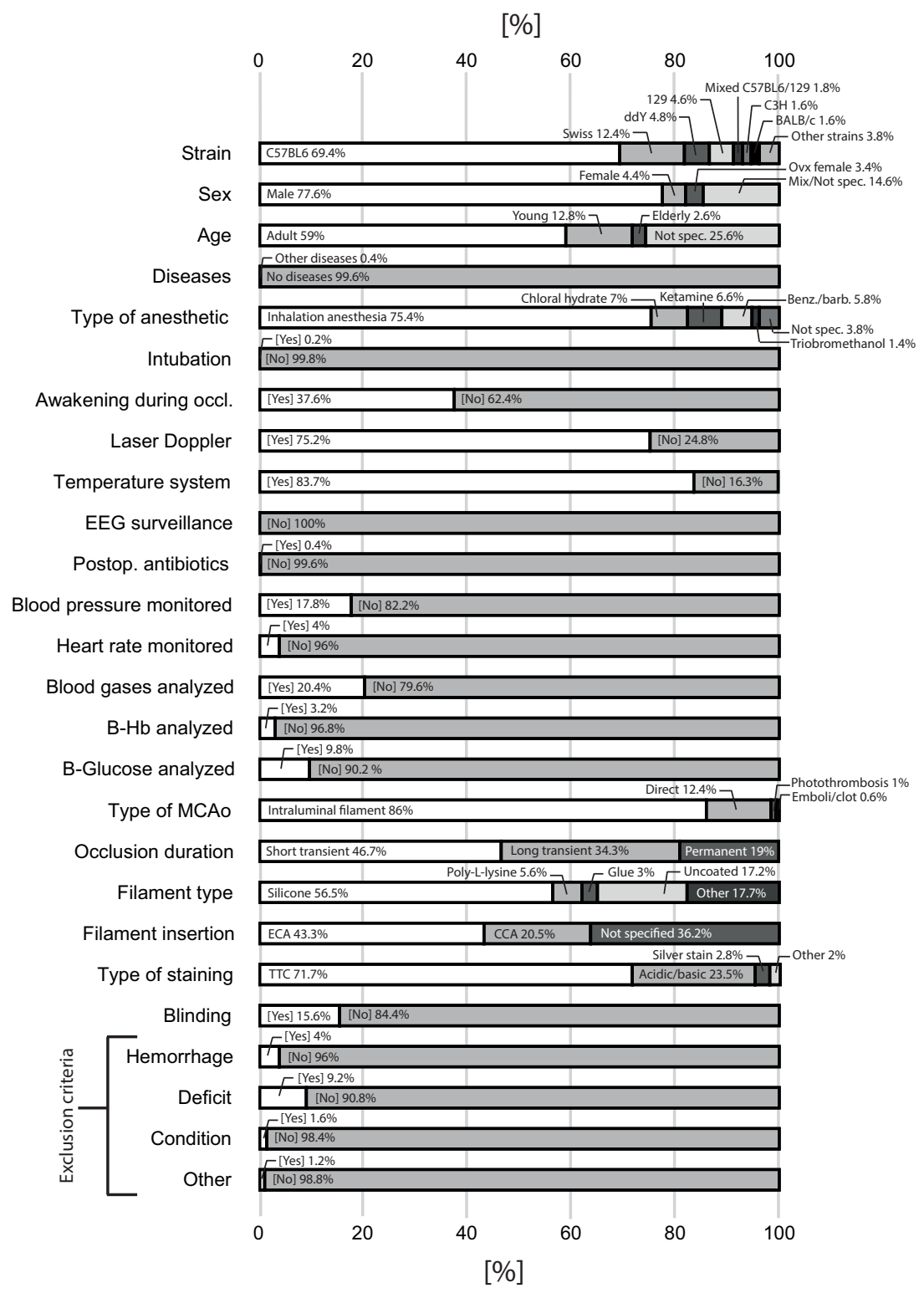

Figure 12. Frequencies of registered categories in the $\mathbf{5 0 0}$ mouse

control groups. The figure also includes variables that were omitted from statistical analysis due to too few articles providing these data. Some variable names are abbreviated, see Paper V for extended descriptions. EEG=Electroencephalography; B=Blood; MCAo=Middle cerebral artery occlusion; TTC=Triphenyl tetrazolium chloride; ECA=External carotid artery; CCA=Common carotid artery. 
confounders, there is complexity and heterogeneity in the underlying experiments that is far beyond our reach, such as the impact of different rat vendors and the skill of the surgeon. For mathematical reasons, categories have also been reduced to larger categories, meaning that differences within categories may be lost.

Among the drawbacks of Paper IV is that coefficients of variation of the infarct size turned out higher than expected. In the comparison between groups, the p-value was just above the significance level and it could be that a difference would have been found with a lower outcome variation or larger groups. Efforts to increase statistical power, e.g. using large groups (n-value of Paper IV was approximately four times the average in similar preclinical stroke studies [133]) were unfortunately not sufficient. Another possible weakness of Paper IV is that the animals were allowed to survive only for 24 hours after induction of ischemia. This could potentially limit generalizability since the infarct can change also after this. However, infarct measurement after 24 $\mathrm{h}$ has been used both in studies where estrogens were neuroprotective $[97,162]$ and neurodamaging [101, 102] previously.

\subsection{Future perspectives}

Regarding HRT, the pros and cons have been widely debated for over a decade, especially subsequent to the publication of the results from the WHI study [96]. Since that study was prematurely ended due to increased risk of cardiovascular diseases and breast cancer, the prescription was dramatically reduced [173]. Even though the approach is more balanced today, the recommendation is still that HRT should not be used without a clear indication, i.e. not for disease prevention but for relief of menopausal symptoms [164, 174]. The goal for the future has been, and still is, to elucidate when and how female sex hormones exert what effects. Hopefully then it would be possible to isolate the beneficial actions, either by using the right timing, dose or route, or the right pathway e.g. by means of receptor-specific ligands. However, the fairly slow progress in the field despite substantial research efforts should perhaps be interpreted as a reason to question the existing animal experimental paradigm. As has been described in this thesis, even for studies only focusing on the neurological effects of estrogens, the results diverge. Numerous studies on different specific effects of estrogens have been published, but to put all the pieces together to get the big picture is not an easy thing to do. If the ambition is to extrapolate and translate the animal findings from bench to bedside, it might be necessary to shift focus to more sophisticated animal models more closely mimicking the human situation.

The validity of animal models has been a hot topic in the stroke field in general, and particularly regarding neuroprotection. Several possible explanations have been suggested to account for the repeated translational failures, e.g. deficiencies in reporting, statistical shortcomings, lack of blinding and randomization [51], as discussed previously in this thesis. The fact that bias in preclinical studies has been suggested to, at least in part, account for failures in the transition of stroke therapies from animal experiments to the clinic indicates that models might be valid if used 
and interpreted properly [13, 60]. There are indeed several promising initiatives providing hope for the future, e.g. the efforts to reduce publication bias by scientific journals dedicated to publishing negative results (e.g. Journal of Negative Results in Biomedicine) and journals not excluding papers based on perceived impact but rather scientific quality (e.g. Scientific Reports, PLOS ONE). And recently, an innovative preclinical stroke study conducted with the same stringency as clinical trials with a randomized controlled multicenter design was published [175]. This could be a step in the right direction to reach large group sizes and in addition, through methodological differences between laboratories (method for ischemia induction, strains etc.), further examine the robustness of results, and perhaps better mimicking the clinical situation where the infarcts are heterogenous [44]. The consequence might be fewer preclinical studies, but of better quality and therefore of more lasting value. However, to substantially boost group sizes in all studies is perhaps neither possible nor desirable. Studies of primarily explorative and hypothesis generating nature may be well advised to instead strive for lower variability and mortality (as discussed in Papers II and $\mathrm{V}$ ) to reach adequate statistical power. 


\section{Acknowledgements}

I want to express my sincere gratitude towards everyone who has helped and supported me in various ways throughout this process. In particular, I would like to thank the following people:

Jakob Ström, my main supervisor, older brother in science and dear friend. For introducing me to research early on in medical school and for trusting me with responsibility in our projects already from the beginning. For always sharing your knowledge so generously and for countless hours of stimulating and amusing conversations about work and all other parts of life. Your passion, curiosity and ambition has inspired me in many ways and continues to do so.

Elvar Theodorsson, my co-supervisor. For allowing me to make my own decisions while at the same time always being available to support and share your vast experience. Your ability to create an environment that is both challenging and comfortable is admirable.

Annette Theodorsson, my co-supervisor. For your never-ceasing enthusiasm and for always being so welcoming and encouraging.

Other members of our research team: Hua Dock for contributing with your microsurgical skills and for company in the lab as well as the office. Julia Slezak for your positive attitude combined with a sharp mind, and for enjoyable coffee breaks. Katrin Ivars and Robert Ihnatko for company in the office. Johanna Gudjonsdottir for good collaboration during your summer project in the lab.

All the wonderful co-workers at the department of Clinical Chemistry. Special thanks to professor emeritus Bertil Kågedal, for encouragement all the way from my first year in medical school throughout my $\mathrm{PhD}$ project.

The staff at the animal facility, for always being so helpful and for taking such good care of the animals.

My parents, Åsa Ingberg and Claes-Mårten Ingberg for unconditional love and support. My brothers, Svante Ingberg and Arvid Ingberg, for all we have been through together and for knowing how to make me laugh.

All my dear friends in Sweden and around the world. For always being there when I need you and for making my life more fun and interesting. 


\section{References}

1. Theodorsson, A. and E. Theodorsson, Estradiol increases brain lesions in the cortex and lateral striatum after transient occlusion of the middle cerebral artery in rats: no effect of ischemia on galanin in the stroke area but decreased levels in the hippocampus. Peptides, 2005. 26(11): p. 2257-64.

2. Marsh, J.D. and S.G. Keyrouz, Stroke prevention and treatment. J Am Coll Cardiol, 2010. 56(9): p. 68391.

3. $\quad$ Donnan, G.A., et al., Stroke. Lancet, 2008. 371(9624): p. 1612-23.

4. Lozano, R., et al., Global and regional mortality from 235 causes of death for 20 age groups in 1990 and 2010: a systematic analysis for the Global Burden of Disease Study 2010. Lancet, 2012. 380(9859): p. 2095-128.

5. Murray, C.J., et al., Disability-adjusted life years (DALYs) for 291 diseases and injuries in 21 regions, 1990-2010: a systematic analysis for the Global Burden of Disease Study 2010. Lancet, 2012. 380(9859): p. 2197-223.

6. Meairs, S., et al., Stroke research priorities for the next decade--A representative view of the European scientific community. Cerebrovasc Dis, 2006. 22(2-3): p. 75-82.

7. Smith, W.S., S. Johnston, and J. Hemphill, III. , Cerebrovascular Diseases. , in Harrison's Principles of Internal Medicine D. Kasper, et al., Editors. 2015, McGraw-Hill: New York, NY.

8. Go, S. and D.J. Worman, Stroke, Transient Ischemic Attack and Cervical Artery Dissection, in Tintinalli's Emergency Medicine: A Comprehensive Study Guide, J.E. Tintinalli, et al., Editors. 2011, McGraw-Hill: New York, NY.

9. Brouns, R. and P.P. De Deyn, The complexity of neurobiological processes in acute ischemic stroke. Clin Neurol Neurosurg, 2009. 111(6): p. 483-95.

10. Jin, R., G. Yang, and G. Li, Inflammatory mechanisms in ischemic stroke: role of inflammatory cells. J Leukoc Biol, 2010. 87(5): p. 779-89.

11. Niizuma, K., et al., Mitochondrial and apoptotic neuronal death signaling pathways in cerebral ischemia. Biochim Biophys Acta, 2010. 1802(1): p. 92-9.

12. Kunz, A., U. Dirnagl, and P. Mergenthaler, Acute pathophysiological processes after ischaemic and traumatic brain injury. Best Pract Res Clin Anaesthesiol, 2010. 24(4): p. 495-509.

13. Dirnagl, U. and M. Endres, Found in translation: preclinical stroke research predicts human pathophysiology, clinical phenotypes, and therapeutic outcomes. Stroke, 2014. 45(5): p. 1510-8.

14. Schwamm, L.H., et al., Temporal trends in patient characteristics and treatment with intravenous thrombolysis among acute ischemic stroke patients at Get With The Guidelines-Stroke hospitals. Circ Cardiovasc Qual Outcomes, 2013. 6(5): p. 543-9.

15. Asplund, K., et al., Effects of extending the time window of thrombolysis to 4.5 hours: observations in the Swedish stroke register (riks-stroke). Stroke, 2011. 42(9): p. 2492-7.

16. Berkowitz, A.L., et al., Worldwide reported use of IV tissue plasminogen activator for acute ischemic stroke. Int J Stroke, 2014. 9(3): p. 349-55.

17. Stroke Unit Trialists, C., Organised inpatient (stroke unit) care for stroke. Cochrane Database Syst Rev, 2013. 9: p. CD000197. 
18. Dirnagl, U., Pathobiology of injury after stroke: the neurovascular unit and beyond. Ann N Y Acad Sci, 2012. 1268: p. 21-5.

19. Langhorne, P., L. de Villiers, and J.D. Pandian, Applicability of stroke-unit care to low-income and middleincome countries. Lancet Neurol, 2012. 11(4): p. 341-8.

20. Falk-Delgado, A., et al., Improved clinical outcome 3 months after endovascular treatment, including thrombectomy, in patients with acute ischemic stroke: a meta-analysis. J Neurointerv Surg, 2015.

21. O’Brien, M.D. and A.G. Waltz, Transorbital approach for occluding the middle cerebral artery without craniectomy. Stroke, 1973. 4(2): p. 201-6.

22. Suzuki, J., et al., Production of various models of cerebral infarction in the dog by means of occlusion of intracranial trunk arteries. Stroke, 1980. 11(4): p. 337-41.

23. Boltze, J., et al., Permanent middle cerebral artery occlusion in sheep: a novel large animal model of focal cerebral ischemia. J Cereb Blood Flow Metab, 2008. 28(12): p. 1951-64.

24. Watanabe, O., A.M. Bremer, and C.R. West, Experimental regional cerebral ischemia in the middle cerebral artery territory in primates. Part 1: Angio-anatomy and description of an experimental model with selective embolization of the internal carotid artery bifurcation. Stroke, 1977. 8(1): p. 61-70.

25. Hudgins, W.R. and J.H. Garcia, Transorbital approach to the middle cerebral artery of the squirrel monkey: a technique for experimental cerebral infarction applicable to ultrastructural studies. Stroke, 1970. 1(2): p. 107-11.

26. Koizumi, J., et al., Experimental studies of ischemic brain edema. 1. A new experimental model of cerebral embolism in rats in which recirculation can be introduced in the ischemic area. Jpn J Stroke, 1986(8): p. 1-8.

27. Longa, E.Z., et al., Reversible middle cerebral artery occlusion without craniectomy in rats. Stroke, 1989. 20(1): p. 84-91.

28. Hossmann, K.A., The two pathophysiologies of focal brain ischemia: implications for translational stroke research. J Cereb Blood Flow Metab, 2012. 32(7): p. 1310-6.

29. Tamura, A., et al., Focal cerebral ischaemia in the rat: 1 . Description of technique and early neuropathological consequences following middle cerebral artery occlusion. J Cereb Blood Flow Metab, 1981. 1(1): p. 53-60.

30. Robinson, R.G., et al., Effect of experimental cerebral infarction in rat brain on catecholamines and behaviour. Nature, 1975. 255(5506): p. 332-4.

31. Strom, J.O., et al., Different methods for administering 17beta-estradiol to ovariectomized rats result in opposite effects on ischemic brain damage. BMC Neurosci, 2010. 11: p. 39.

32. Robinson, M.J., et al., Reduction of local cerebral blood flow to pathological levels by endothelin-1 applied to the middle cerebral artery in the rat. Neurosci Lett, 1990. 118(2): p. 269-72.

33. Sharkey, J., I.M. Ritchie, and P.A. Kelly, Perivascular microapplication of endothelin-1: a new model of focal cerebral ischaemia in the rat. J Cereb Blood Flow Metab, 1993. 13(5): p. 865-71.

34. Watson, B.D., et al., Induction of reproducible brain infarction by photochemically initiated thrombosis. Ann Neurol, 1985. 17(5): p. 497-504.

35. Kudo, M., et al., An animal model of cerebral infarction. Homologous blood clot emboli in rats. Stroke, 
1982. 13(4): p. 505-8.

36. Orset, C., et al., Mouse model of in situ thromboembolic stroke and reperfusion. Stroke, 2007. 38(10): p. 2771-8.

37. Prinz, V. and M. Endres, Modeling focal cerebral ischemia in rodents: introduction and overview, in Rodent Models of Stroke, U. Dirnagl, Editor. 2010, Humana Press: New York, NY.

38. Traystman, R.J., Animal models of focal and global cerebral ischemia. ILAR J, 2003. 44(2): p. 85-95.

39. Lowry, O.H., et al., Effect of Ischemia on Known Substrates and Cofactors of the Glycolytic Pathway in Brain. J Biol Chem, 1964. 239: p. 18-30.

40. Siemkowicz, E. and A.J. Hansen, Clinical restitution following cerebral ischemia in hypo-, normo- and hyperglycemic rats. Acta Neurol Scand, 1978. 58(1): p. 1-8.

41. Pulsinelli, W.A. and J.B. Brierley, A new model of bilateral hemispheric ischemia in the unanesthetized rat. Stroke, 1979. 10(3): p. 267-72.

42. Eklof, B. and B.K. Siesjo, The effect of bilateral carotid artery ligation upon acid-base parameters and substrate levels in the rat brain. Acta Physiol Scand, 1972. 86(4): p. 528-38.

43. Kirino, T., Delayed neuronal death in the gerbil hippocampus following ischemia. Brain Res, 1982. 239(1): p. 57-69.

44. Broussalis, E., et al., Current therapies in ischemic stroke. Part B. Future candidates in stroke therapy and experimental studies. Drug Discov Today, 2012. 17(13-14): p. 671-84.

45. Endres, M., et al., Improving outcome after stroke: overcoming the translational roadblock. Cerebrovasc Dis, 2008. 25(3): p. 268-78.

46. O’Collins, V.E., et al., 1,026 experimental treatments in acute stroke. Ann Neurol, 2006. 59(3): p. $467-77$.

47. Lee, D.S., et al., Meta-analysis of the effects of endothelin receptor blockade on survival in experimental heart failure. J Card Fail, 2003. 9(5): p. 368-74.

48. van Hout, G.P., et al., Translational failure of anti-inflammatory compounds for myocardial infarction: a meta-analysis of large animal models. Cardiovasc Res, 2015.

49. Bebarta, V., D. Luyten, and K. Heard, Emergency medicine animal research: does use of randomization and blinding affect the results? Acad Emerg Med, 2003. 10(6): p. 684-7.

50. Ioannidis, J.P., Why most published research findings are false. PLoS Med, 2005. 2(8): p. e124.

51. Dirnagl, U., Bench to bedside: the quest for quality in experimental stroke research. J Cereb Blood Flow Metab, 2006. 26(12): p. 1465-78.

52. Russel, W. and R. Burch, The principles of humane experimental technique. Universities Federation for Animal Welfare, Wheathamstead, England, 1959 (as reprinted 1992).

53. Sena, E.S., et al., Systematic reviews and meta-analysis of preclinical studies: why perform them and how to appraise them critically. J Cereb Blood Flow Metab, 2014. 34(5): p. 737-42.

54. O’Rourke, K., An historical perspective on meta-analysis: dealing quantitatively with varying study results. J R Soc Med, 2007. 100(12): p. 579-82. 
55. Report on Certain Enteric Fever Inoculation Statistics. Br Med J, 1904. 2(2288): p. 1243-6.

56. Glass, G., Primary, secondary and meta-analysis of research. Educ Researcher, 1976(10): p. 3-8.

57. Cochrane. [cited 2015 November 18]; Available from: http://www.cochrane.org/.

58. Korevaar, D.A., L. Hooft, and G. ter Riet, Systematic reviews and meta-analyses of preclinical studies: publication bias in laboratory animal experiments. Lab Anim, 2011. 45(4): p. 225-30.

59. Bath, P.M., et al., Effects of NXY-059 in experimental stroke: an individual animal meta-analysis. Br J Pharmacol, 2009. 157(7): p. 1157-71.

60. Crossley, N.A., et al., Empirical evidence of bias in the design of experimental stroke studies: a metaepidemiologic approach. Stroke, 2008. 39(3): p. 929-34.

61. CAMARADES. [cited 2015 November 18]; Available from: http://www.dcn.ed.ac.uk/camarades/.

62. SYCRLE. [cited 2015 November 18]; Available from: https://www.radboudumc.nl/Research/ Organisationofresearch/Departments/cdl/SYRCLE/Pages/AboutSYRCLE.aspx.

63. Salpeter, S.R., et al., Mortality associated with hormone replacement therapy in younger and older women: a meta-analysis. J Gen Intern Med, 2004. 19(7): p. 791-804.

64. Bath, P.M. and L.J. Gray, Association between hormone replacement therapy and subsequent stroke: a meta-analysis. BMJ, 2005. 330(7487): p. 342.

65. Gu, H., et al., Risk of stroke in healthy postmenopausal women during and after hormone therapy: a metaanalysis. Menopause, 2014. 21(11): p. 1204-10.

66. Main, C., et al., Hormone therapy for preventing cardiovascular disease in post-menopausal women. Cochrane Database Syst Rev, 2013. 4: p. CD002229.

67. Koellhoffer, E.C. and L.D. McCullough, The effects of estrogen in ischemic stroke. Transl Stroke Res, 2013. 4(4): p. 390-401.

68. Manwani, B. and L.D. McCullough, Sexual dimorphism in ischemic stroke: lessons from the laboratory. Womens Health (Lond Engl), 2011. 7(3): p. 319-39.

69. Carswell, H.V., I.M. Macrae, and T.D. Farr, Complexities of oestrogen in stroke. Clin Sci (Lond), 2010. 118(6): p. 375-89.

70. Suzuki, S., C.M. Brown, and P.M. Wise, Neuroprotective effects of estrogens following ischemic stroke. Front Neuroendocrinol, 2009. 30(2): p. 201-11.

71. Singh, M., et al., Estrogens and progesterone as neuroprotectants: what animal models teach us. Front Biosci, 2008. 13: p. 1083-9.

72. Gibson, C.L., et al., Estrogens and experimental ischemic stroke: a systematic review. J Cereb Blood Flow Metab, 2006. 26(9): p. 1103-13.

73. Strom, J.O., A. Theodorsson, and E. Theodorsson, Dose-related neuroprotective versus neurodamaging effects of estrogens in rat cerebral ischemia: a systematic analysis. J Cereb Blood Flow Metab, 2009. 29(8): p. 1359-72.

74. Shampo, M.A., R.A. Kyle, and D.P. Steensma, Adolf Butenandt--Nobel Prize for chemistry. Mayo Clin Proc, 2012. 87(4): p. e27. 
75. Levin, E. and S. Hammes, Estrogens and Progestins, in Goodman \& Gilman's The Pharmacological Basis of Therapeutics, L. Brunton, B. Chabner, and B. Knollman, Editors. 2011, McGraw-Hill: New York, NY.

76. Gillies, G.E. and S. McArthur, Estrogen actions in the brain and the basis for differential action in men and women: a case for sex-specific medicines. Pharmacol Rev, 2010. 62(2): p. 155-98.

77. Korach KS, M.S., Davis VL, Estrogens, in Principles of Pharmacology, M. PL, Editor., Chapman \& Hall: New York. p. 809-25.

78. Levin, E. and S. Hammes, Hormones and Hormone Antagonists, in Goodman \& Gilman’s The Pharmacological Basis of Therapeutics, C.B. Brunton LL, Knollman BC, Editor. 2011, McGraw-Hill: New York.

79. Molina, P., Female Reproductive System, in Endocrine Physiology, P. Molina, Editor. 2015, McGraw-Hill: New York, NY.

80. Caligioni, C.S., Assessing reproductive status/stages in mice. Curr Protoc Neurosci, 2009. Appendix 4: p. Appendix 4I.

81. Shaikh, A.A. and S.A. Shaikh, Adrenal and ovarian steroid secretion in the rat estrous cycle temporally related to gonadotropins and steroid levels found in peripheral plasma. Endocrinology, 1975. 96(1): p. 37 44.

82. Goldman, J.M., A.S. Murr, and R.L. Cooper, The rodent estrous cycle: characterization of vaginal cytology and its utility in toxicological studies. Birth Defects Res B Dev Reprod Toxicol, 2007. 80(2): p. 84-97.

83. Westwood, F.R., The female rat reproductive cycle: a practical histological guide to staging. Toxicol Pathol, 2008. 36(3): p. 375-84.

84. Felicio, L.S., J.F. Nelson, and C.E. Finch, Longitudinal studies of estrous cyclicity in aging C57BL/6J mice: II. Cessation of cyclicity and the duration of persistent vaginal cornification. Biol Reprod, 1984. 31(3): p. 446-53.

85. Dahlman-Wright, K., et al., International Union of Pharmacology. LXIV. Estrogen receptors. Pharmacol Rev, 2006. 58(4): p. 773-81.

86. Nilsson, S. and J.A. Gustafsson, Estrogen receptors: therapies targeted to receptor subtypes. Clin Pharmacol Ther, 2011. 89(1): p. 44-55.

87. Jensen, E.V., From chemical warfare to breast cancer management. Nat Med, 2004. 10(10): p. $1018-21$.

88. Kuiper, G.G., et al., Cloning of a novel receptor expressed in rat prostate and ovary. Proc Natl Acad Sci U S A, 1996. 93(12): p. 5925-30.

89. Harrington, W.R., et al., Activities of estrogen receptor alpha- and beta-selective ligands at diverse estrogen responsive gene sites mediating transactivation or transrepression. Mol Cell Endocrinol, 2003. 206(1-2): p. 13-22.

90. Lisabeth, L. and C. Bushnell, Stroke risk in women: the role of menopause and hormone therapy. Lancet Neurol, 2012. 11(1): p. 82-91.

91. Hall, E.D., K.E. Pazara, and K.L. Linseman, Sex differences in postischemic neuronal necrosis in gerbils. J Cereb Blood Flow Metab, 1991. 11(2): p. 292-8.

92. Dubal, D.B., et al., Estradiol protects against ischemic injury. J Cereb Blood Flow Metab, 1998. 18(11): p. 1253-8. 
93. Simpkins, J.W., et al., Estrogens may reduce mortality and ischemic damage caused by middle cerebral artery occlusion in the female rat. J Neurosurg, 1997. 87(5): p. 724-30.

94. Falkeborn, M., et al., Hormone replacement therapy and the risk of stroke. Follow-up of a populationbased cohort in Sweden. Arch Intern Med, 1993. 153(10): p. 1201-9.

95. Paganini-Hill, A., R.K. Ross, and B.E. Henderson, Postmenopausal oestrogen treatment and stroke: a prospective study. BMJ, 1988. 297(6647): p. 519-22.

96. Rossouw, J.E., et al., Risks and benefits of estrogen plus progestin in healthy postmenopausal women: principal results From the Women's Health Initiative randomized controlled trial. JAMA, 2002. 288(3): p. 321-33.

97. Wise, P.M. and D.B. Dubal, Estradiol protects against ischemic brain injury in middle-aged rats. Biol Reprod, 2000. 63(4): p. 982-5.

98. Alkayed, N.J., et al., Neuroprotective effects of female gonadal steroids in reproductively senescent female rats. Stroke, 2000. 31(1): p. 161-8.

99. Dang, J., et al., Gonadal steroids prevent cell damage and stimulate behavioral recovery after transient middle cerebral artery occlusion in male and female rats. Brain Behav Immun, 2011. 25(4): p. 715-26.

100. Leon, R.L., et al., Worsened outcome from middle cerebral artery occlusion in aged rats receiving 17betaestradiol. Endocrinology, 2012. 153(7): p. 3386-93.

101. Gordon, K.B., I.M. Macrae, and H.V. Carswell, Effects of 17beta-oestradiol on cerebral ischaemic damage and lipid peroxidation. Brain Res, 2005. 1036(1-2): p. 155-62.

102. Bingham, D., I.M. Macrae, and H.V. Carswell, Detrimental effects of 17beta-oestradiol after permanent middle cerebral artery occlusion. J Cereb Blood Flow Metab, 2005. 25(3): p. 414-20.

103. Prentice, R.L., et al., Benefits and risks of postmenopausal hormone therapy when it is initiated soon after menopause. Am J Epidemiol, 2009. 170(1): p. 12-23.

104. Suzuki, S., et al., Timing of estrogen therapy after ovariectomy dictates the efficacy of its neuroprotective and antiinflammatory actions. Proc Natl Acad Sci U S A, 2007. 104(14): p. 6013-8.

105. Selvamani, A. and F. Sohrabji, Reproductive age modulates the impact of focal ischemia on the forebrain as well as the effects of estrogen treatment in female rats. Neurobiol Aging, 2010. 31(9): p. 1618-28.

106. Carswell, H.V., et al., Differential effects of 17beta-estradiol upon stroke damage in stroke prone and normotensive rats. J Cereb Blood Flow Metab, 2004. 24(3): p. 298-304.

107. Santizo, R.A., et al., Loss of benefit from estrogen replacement therapy in diabetic ovariectomized female rats subjected to transient forebrain ischemia. Brain Res, 2002. 956(1): p. 86-95.

108. Theodorsson, A., et al., Serum concentrations of 17beta-estradiol in ovariectomized rats during two times six weeks crossover treatment by daily injections in comparison with slow-release pellets. Scand J Clin Lab Invest, 2005. 65(8): p. 699-705.

109. Strom, J.O., E. Theodorsson, and A. Theodorsson, Order of magnitude differences between methods for maintaining physiological 17beta-oestradiol concentrations in ovariectomized rats. Scand J Clin Lab Invest, 2008. 68(8): p. 814-22.

110. Isaksson, I.M., et al., Methods for 17beta-oestradiol administration to rats. Scand J Clin Lab Invest, 2011. 71(7): p. 583-92. 
111. Culmsee, C., et al., Neuroprotection by estrogens in a mouse model of focal cerebral ischemia and in cultured neurons: evidence for a receptor-independent antioxidative mechanism. J Cereb Blood Flow Metab, 1999. 19(11): p. 1263-9.

112. Wang, X., et al., Neuroprotective effects of 17beta-estradiol and nonfeminizing estrogens against H2O2 toxicity in human neuroblastoma SK-N-SH cells. Mol Pharmacol, 2006. 70(1): p. 395-404.

113. Kumar, S., et al., Role of estrogen receptors in pro-oxidative and anti-oxidative actions of estrogens: a perspective. Biochim Biophys Acta, 2010. 1800(10): p. 1127-35.

114. Czlonkowska, A., et al., Gender differences in neurological disease: role of estrogens and cytokines. Endocrine, 2006. 29(2): p. 243-56.

115. Santizo, R.A., et al., Effects of estrogen on leukocyte adhesion after transient forebrain ischemia. Stroke, 2000. 31(9): p. 2231-5.

116. Yong, Y., et al., 17beta-estradiol potentiates ischemia-reperfusion injury in diabetic ovariectomized female rats. Brain Res, 2005. 1054(2): p. 192-9.

117. Alkayed, N.J., et al., Estrogen and Bcl-2: gene induction and effect of transgene in experimental stroke. J Neurosci, 2001. 21(19): p. 7543-50.

118. Lebesgue, D., et al., Estradiol rescues neurons from global ischemia-induced cell death: multiple cellular pathways of neuroprotection. Steroids, 2009. 74(7): p. 555-61.

119. Suzuki, S., et al., Estradiol enhances neurogenesis following ischemic stroke through estrogen receptors alpha and beta. J Comp Neurol, 2007. 500(6): p. 1064-75.

120. Brann, D.W., et al., Steroid hormone effects on NMDA receptor binding and NMDA receptor mRNA levels in the hypothalamus and cerebral cortex of the adult rat. Neuroendocrinology, 1993. 58(6): p. 66672.

121. Sato, K., et al., Estrogens inhibit l-glutamate uptake activity of astrocytes via membrane estrogen receptor alpha. J Neurochem, 2003. 86(6): p. 1498-505.

122. Strom, J.O., et al., Effects of high and low 17beta-estradiol doses on focal cerebral ischemia: negative results. Sci Rep, 2013. 3: p. 3111.

123. Scherbakov, N., U. Dirnagl, and W. Doehner, Body weight after stroke: lessons from the obesity paradox. Stroke, 2011. 42(12): p. 3646-50.

124. Dubal, D.B., et al., Differential modulation of estrogen receptors (ERs) in ischemic brain injury: a role for ERalpha in estradiol-mediated protection against delayed cell death. Endocrinology, 2006. 147(6): p. 307684.

125. Dubal, D.B., et al., Estrogen receptor alpha, not beta, is a critical link in estradiol-mediated protection against brain injury. Proc Natl Acad Sci U S A, 2001. 98(4): p. 1952-7.

126. Carswell, H.V., et al., Neuroprotection by a selective estrogen receptor beta agonist in a mouse model of global ischemia. Am J Physiol Heart Circ Physiol, 2004. 287(4): p. H1501-4.

127. Sampei, K., et al., Stroke in estrogen receptor-alpha-deficient mice. Stroke, 2000. 31(3): p. 738-43; discussion 744 .

128. Southam, C. and J. Ehrlich, Effects of Extract of western red-cedar heartwood on certain wood-decaying fungi in culture. Phytopathology, 1943(33): p. 517-24. 
129. Kendig, E.L., H.H. Le, and S.M. Belcher, Defining hormesis: evaluation of a complex concentration response phenomenon. Int J Toxicol, 2010. 29(3): p. 235-46.

130. Calabrese, E.J., Hormesis is central to toxicology, pharmacology and risk assessment. Hum Exp Toxicol, 2010. 29(4): p. 249-61.

131. Drug model may be wrong for low doses [cited 2015 November 20]; Available from: http://www.upi.com/ Health_News/2006/12/27/Drug-model-may-be-wrong-for-low-doses/UPI-25921167249853/.

132. Calabrese, E.J., Estrogen and related compounds: biphasic dose responses. Crit Rev Toxicol, 2001. 31(45): p. 503-15.

133. Strom, J.O., et al., Method parameters' impact on mortality and variability in rat stroke experiments: a meta-analysis. BMC Neurosci, 2013. 14(1): p. 41.

134. Aspey, B.S., et al., Temporary middle cerebral artery occlusion in the rat: consistent protocol for a model of stroke and reperfusion. Neuropathol Appl Neurobiol, 2000. 26(3): p. 232-42.

135. Haim, S., et al., Serum levels of sex hormones and corticosterone throughout 4- and 5-day estrous cycles in Fischer 344 rats and their simulation in ovariectomized females. J Endocrinol Invest, 2003. 26(10): p. 1013-22.

136. Tang, A.C., et al., Effects of long-term estrogen replacement on social investigation and social memory in ovariectomized C57BL/6 mice. Horm Behav, 2005. 47(3): p. 350-7.

137. Dabrosin, C., et al., Estradiol promotes growth and angiogenesis in polyoma middle T transgenic mouse mammary tumor explants. Breast Cancer Res Treat, 2003. 78(1): p. 1-6.

138. Liu, J.W., et al., Estrogen replacement in ovariectomized rats results in physiologically significant levels of circulating progesterone, and co-administration of progesterone markedly reduces the circulating estrogen. Endocrine, 1997. 6(2): p. 125-31.

139. Babiker, F.A., et al., Oestrogen modulates cardiac ischaemic remodelling through oestrogen receptorspecific mechanisms. Acta Physiol (Oxf), 2007. 189(1): p. 23-31.

140. Moran, A.L., et al., Estradiol replacement reverses ovariectomy-induced muscle contractile and myosin dysfunction in mature female mice. J Appl Physiol, 2007. 102(4): p. 1387-93.

141. Levin-Allerhand, J.A., K. Sokol, and J.D. Smith, Safe and effective method for chronic 17beta-estradiol administration to mice. Contemp Top Lab Anim Sci, 2003. 42(6): p. 33-5.

142. Mannino, C.A., et al., Pharmacokinetics and effects of 17beta-estradiol and progesterone implants in ovariectomized rats. J Pain, 2005. 6(12): p. 809-16.

143. Bridges, R.S., A quantitative analysis of the roles of dosage, sequence, and duration of estradiol and progesterone exposure in the regulation of maternal behavior in the rat. Endocrinology, 1984. 114(3): p. 930-40.

144. Cohen, P.E. and S.R. Milligan, Silastic implants for delivery of oestradiol to mice. J Reprod Fertil, 1993. 99(1): p. 219-23.

145. Jasnow, A.M., J. Schulkin, and D.W. Pfaff, Estrogen facilitates fear conditioning and increases corticotropin-releasing hormone mRNA expression in the central amygdala in female mice. Horm Behav, 2006. 49(2): p. 197-205.

146. Kalliokoski, O., et al., Serum concentrations of buprenorphine after oral and parenteral administration in 
male mice. Vet J, 2011. 187(2): p. 251-4.

147. Garner, J.P., Stereotypies and other abnormal repetitive behaviors: potential impact on validity, reliability, and replicability of scientific outcomes. ILAR J, 2005. 46(2): p. 106-17.

148. Farr, T.D. and R.C. Trueman, Functional Assessment of Subcortical Ischemia, in Animal Models of Movement Disorders, E.L. Lane and S.B. Dunnet, Editors. 2011.

149. Strom, J.O., A. Theodorsson, and E. Theodorsson, Substantial discrepancies in 17beta-oestradiol concentrations obtained with three different commercial direct radioimmunoassay kits in rat sera. Scand J Clin Lab Invest, 2008. 68(8): p. 806-13.

150. Haisenleder, D.J., et al., Estimation of estradiol in mouse serum samples: evaluation of commercial estradiol immunoassays. Endocrinology, 2011. 152(11): p. 4443-7.

151. Gordon, M.N., et al., Effective oral administration of 17 beta-estradiol to female C57BL/6J mice through the drinking water. Biol Reprod, 1986. 35(5): p. 1088-95.

152. Robbins, M.T., et al., Effect of estrogen on bladder nociception in rats. J Urol, 2010. 183(3): p. 1201-5.

153. Bederson, J.B., et al., Evaluation of 2,3,5-triphenyltetrazolium chloride as a stain for detection and quantification of experimental cerebral infarction in rats. Stroke, 1986. 17(6): p. 1304-8.

154. Li, F., et al., Delayed triphenyltetrazolium chloride staining remains useful for evaluating cerebral infarct volume in a rat stroke model. J Cereb Blood Flow Metab, 1997. 17(10): p. 1132-5.

155. Goldlust, E.J., et al., Automated measurement of infarct size with scanned images of triphenyltetrazolium chloride-stained rat brains. Stroke, 1996. 27(9): p. 1657-62.

156. Sughrue, M.E., et al., An improved test of neurological dysfunction following transient focal cerebral ischemia in rats. J Neurosci Methods, 2006. 151(2): p. 83-9.

157. Lee, J.Y., et al., Estrogen decreases zinc transporter 3 expression and synaptic vesicle zinc levels in mouse brain. J Biol Chem, 2004. 279(10): p. 8602-7.

158. Cleuren, A.C., et al., Short-term ethinyl estradiol treatment suppresses inferior caval vein thrombosis in obese mice. Thromb Haemost, 2009. 102(5): p. 993-1000.

159. Mercado-Feliciano, M. and R.M. Bigsby, The polybrominated diphenyl ether mixture DE-71 is mildly estrogenic. Environ Health Perspect, 2008. 116(5): p. 605-11.

160. IRA. [cited 2015 November 26]; Available from: http://www.innovrsrch.com/faq.asp\#R1.

161. Ma, Y.L., et al., The effects of different doses of estradiol (E2) on cerebral ischemia in an in vitro model of oxygen and glucose deprivation and reperfusion and in a rat model of middle carotid artery occlusion. BMC Neurosci, 2013. 14: p. 118.

162. Toung, T.J., R.J. Traystman, and P.D. Hurn, Estrogen-mediated neuroprotection after experimental stroke in male rats. Stroke, 1998. 29(8): p. 1666-70.

163. Toung, T.K., et al., Estrogen decreases infarct size after temporary focal ischemia in a genetic model of type 1 diabetes mellitus. Stroke, 2000. 31(11): p. 2701-6.

164. de Villiers, T.J., et al., Updated 2013 International Menopause Society recommendations on menopausal hormone therapy and preventive strategies for midlife health. Climacteric, 2013. 16(3): p. 316-37. 
165. Fan, T., et al., 17beta-Estradiol extends ischemic thresholds and exerts neuroprotective effects in cerebral subcortex against transient focal cerebral ischemia in rats. Brain Res, 2003. 993(1-2): p. 10-7.

166. Kim, J.M., et al., Dietary S-allyl-L-cysteine reduces mortality with decreased incidence of stroke and behavioral changes in stroke-prone spontaneously hypertensive rats. Biosci Biotechnol Biochem, 2006. 70(8): p. 1969-71.

167. Clarkson, T.B. and S.E. Appt, Controversies about HRT--lessons from monkey models. Maturitas, 2005. 51(1): p. 64-74.

168. Suhonen, S., et al., Postmenopausal oestrogen replacement therapy with subcutaneous oestradiol implants. Maturitas, 1993. 16(2): p. 123-31.

169. Macleod, M.R., et al., Good laboratory practice: preventing introduction of bias at the bench. Stroke, 2009. 40(3): p. e50-2.

170. Schlattmann, P. and U. Dirnagl, Statistics in experimental cerebrovascular research-comparison of two groups with a continuous outcome variable. J Cereb Blood Flow Metab, 2010. 30(3): p. 474-9.

171. Sterne, J.A. and G. Davey Smith, Sifting the evidence-what's wrong with significance tests? BMJ, 2001. 322(7280): p. 226-31.

172. Schierbeck, L.L., et al., Effect of hormone replacement therapy on cardiovascular events in recently postmenopausal women: randomised trial. BMJ, 2012. 345: p. e6409.

173. Santen, R.J., et al., Postmenopausal hormone therapy: an Endocrine Society scientific statement. J Clin Endocrinol Metab, 2010. 95(7 Suppl 1): p. s1-s66.

174. Boardman, H.M., et al., Hormone therapy for preventing cardiovascular disease in post-menopausal women. Cochrane Database Syst Rev, 2015. 3: p. CD002229.

175. Llovera, G., et al., Results of a preclinical randomized controlled multicenter trial (pRCT): Anti-CD49d treatment for acute brain ischemia. Sci Transl Med, 2015. 7(299): p. 299 ra121. 


\section{Papers}

The articles associated with this thesis have been removed for copyright reasons. For more details about these see:

http://urn.kb.se/resolve?urn=urn:nbn:se:liu:diva-123893 